\title{
The feasibility of imaging subglacial hydrology beneath ice streams with ground-based electromagnetics
}

\author{
KERRY KEY, ${ }^{1,2}$ MATTHEW R. SIEGFRIED ${ }^{1,3}$ \\ ${ }^{1}$ Institute of Geophysics and Planetary Physics, Scripps Institution of Oceanography, University of California, San Diego, \\ La Jolla, CA, USA \\ ${ }^{2}$ Now at Lamont-Doherty Earth Observatory, Columbia University, Palisades, NY, USA \\ ${ }^{3}$ Now at Department of Geophysics, Stanford University, Stanford, CA, USA \\ Correspondence: Kerry Key <kkey@/deo.columbia.edu>
}

\begin{abstract}
Subglacial hydrologic systems in Antarctica and Greenland play a fundamental role in ice-sheet dynamics, yet critical aspects of these systems remain poorly understood due to a lack of observations. Ground-based electromagnetic (EM) geophysical methods are established for mapping groundwater in many environments, but have never been applied to imaging lakes beneath ice sheets. Here, we study the feasibility of passive- and active-source EM imaging for quantifying the nature of subglacial water systems beneath ice streams, with an emphasis on the interfaces between ice and basal meltwater, as well as deeper groundwater in the underlying sediments. We describe a suite of model studies that exam the data sensitivity as a function of ice thickness, water conductivity and hydrologic system geometry for models representative of a subglacial lake and a grounding zone estuary. We show that EM data are directly sensitive to groundwater and can image its lateral and depth extent. By combining the conductivity obtained from EM data with ice thickness and geological structure from conventional geophysical techniques, such as ground-penetrating radar and active seismic surveying, EM data have the potential to provide new insights on the interaction between ice, rock and water at critical ice-sheet boundaries.
\end{abstract}

KEYWORDS: electromagnetic induction, glaciological instruments and methods, subglacial exploration geophysics, subglacial lakes, subglacial sediments

\section{INTRODUCTION}

The presence and movement of water beneath a glacier has long been known to affect the dynamics of the overlying ice (Robin, 1955; Lliboutry, 1964; Weertman, 1964; Röthlisberger, 1972; Kamb, 1987; Siegert and Bamber, 2000; Bell, 2008). As recently as 2005, subglacial water was thought either to reside in isolated water bodies located in bedrock hollows of the slow-moving ice-sheet interior, exerting only a localized influence on ice flow (Kapitsa and others, 1996; Dowdeswell and Siegert, 1999; Siegert and others, 2005; Tabacco and others, 2006), or to be a part of steady-state ice-stream processes required to maintain fast flow (Blankenship and others, 1987; Engelhardt and Kamb, 1997; Christoffersen and Tulaczyk, 2003). Although water transport in regions of rapid ice flow was understood as important for maintaining lubrication in areas where the basal thermal regime would otherwise result in freezing and hardening of the subglacial sediments (Christoffersen and Tulaczyk, 2003; Parizek and others, 2003), changes to water transport were only hypothesized to be associated with long-term dynamics like century-scale ice-stream reorganization (Alley and others, 1994; Anandakrishnan and Alley, 1997; Vaughan and others, 2008).

Recent observations have altered this historical view of Antarctica's subglacial water system. Vertical surface motion captured from satellite-based measurements were interpreted as the surface expression of previously unknown subglacial water movement into and out of lakes at the ice-bed interface (Gray and others, 2005; Wingham and others, 2006; Fricker and others, 2007). Several studies demonstrated that many subglacial lakes exist in areas of fast ice flow, are hydrologically connected and undergo repeated fluctuations in volume over monthly to (likely) decadal timescales (Fricker and others, 2007; Fricker and Scambos, 2009; Smith and others, 2009). A continent-wide survey using automated processing of satellite laser altimetry data (Smith and others, 2009) produced an inventory of 124 lakes causing detectable ice-surface deformation (i.e. 'active' subglacial lakes) at locations different from subglacial lakes mapped with previous methods (Siegert and others, 2005; Wright and Siegert, 2012). Many of these lakes have eluded detection by radio-echo sounding data, suggesting shallow water bodies within regions of saturated sediments (Carter and others, 2017) that could be explained by transient build-up of water behind hydraulic obstacles (Siegert and others, 2014).

The implications of non-steady state transport of Antarctic subglacial water on regional ice dynamics and ice-sheet mass balance are still uncertain. Reports from East Antarctica, West Antarctica and the Antarctic Peninsula suggest that the filling and draining of active subglacial lakes modulates ice velocity (Stearns and others, 2008; Scambos and others, 2011; Siegfried and others, 2016), yet observations from Pine Island Glacier and Thwaites Glacier in the Amundsen Sea region of West Antarctica show no strong correlation between velocity variability and dynamic subglacial hydrology (Joughin and others, 2016; Smith and others, 2016), suggesting that the sensitivity of ice flow to hydrologic change is dependent on the local conditions. Thermomechanical modeling of ice-stream flow suggests that a dynamic water system may play a role in rapid ice flow rearrangement (Elsworth and Suckale, 2016). 
The uneven outflow of fresh subglacial water across the grounding zone and into the ocean cavity (Carter and Fricker, 2012) can disrupt background ocean circulation, resulting in increased ice-shelf basal-melt rates (Jenkins, 2011) and formation of ice-shelf basal channels (Le Brocq and others, 2013; Alley and others, 2016; Marsh and others, 2016). The impact of these basal channels, however, is unknown: while some modeling studies have suggested that uneven melting results in an overall reduction in regionally averaged basal-melt rate and enhanced ice-shelf stability (Gladish and others, 2012; Millgate and others, 2013), others have concluded that structural weakening of an ice shelf due to the presence of basal channels destabilized the ice shelf (Rignot and Steffen, 2008; Vaughan and others, 2012; Sergienko, 2013; Alley and others, 2016). The input of subglacial water into the Southern Ocean also has potentially significant biological implications as the flux of fine sediments and nutrients from the basal environment may act to fertilize the Southern Ocean (Wadham and others, 2013; Vick-Majors, 2016).

Given the potential impacts of dynamic basal water systems, we still have relatively few datasets for studying subglacial hydrological networks and their relation to the larger ice-sheet, biological and oceanographic systems, largely due to the inaccessibility of the environment. Most importantly, while we can estimate changes in the subglacial water storage of subglacial lakes from ground-based and spacebased geodetic methods (Smith and others, 2009; Siegfried and others, 2014, 2016), these techniques cannot measure total water volume of the subglacial system, where water is stored within the system (groundwater, near-surface porewater or at the ice-bed interface), or how water moves between components of the system and is ultimately released into the ocean system. Recent work has highlighted the importance of these issues: a modeling study suggested that up to $50 \%$ of the hydrologic budget for Siple Coast ice streams may be sourced from a groundwater system that has yet to be observed (Christoffersen and others, 2014), while a sediment core from within a subglacial lake suggested the presence of a deeper reservoir of saline water well beneath the ice-bed interface (Michaud and others, 2016). The need for better knowledge on subglacial hydrology was recently recognized as fundamental to answering high-priority scientific questions in Antarctic research (Kennicutt and others, 2014).

Typical glaciological techniques for detailed investigation of subglacial hydrological systems include groundpenetrating radar and active seismic sounding techniques (e.g. Kapitsa and others, 1996; Hubbard and others, 2004). While these tools effectively image stratigraphic horizons that can be used to characterize large, bedrockcontrolled water bodies, for example, Vostok Subglacial Lake and Ellsworth Subglacial Lake (Woodward and others, 2010; Siegert and others, 2011), and may detect the presence of subglacial water in other regions (Hubbard and others, 2004; Christianson and others, 2012; Horgan and others, 2012), neither technique is effective for characterizing the volume of water in thin lakes (Tulaczyk and others, 2014), nor can they quantify the amount of pore-water present in underlying till, preglacial sediments and deeper basement. To improve our ability to map subglacial hydrology, there is a need to employ geophysical techniques that are more sensitive to fluid-content contrasts than geologic contrasts.
In this study, we assess the feasibility of ground-based electromagnetic (EM) methods for constraining the hydrological structure beneath ice streams and outlet glaciers. Active and passive EM methods are well established for mapping groundwater hydrology in non-glaciological environments (e.g. Danielsen and others, 2003; Meqbel and others, 2013; Nenna and others, 2013), yet have seen little attention for glaciological applications. Here, we use a suite of forward modeling and inversions studies to illustrate how ground-based passive- and active-source EM techniques can be adapted for imaging the ice-sheet environment (Fig. 1). Our study is motivated by the success of a recent pilot study using the relatively shallow-sensing airborne EM method in East Antarctica (Foley and others, 2015; Mikucki and others, 2015) and seeks to establish the range of glaciological questions that can be investigated through the application of EM techniques that are well established for other geophysical targets. While our study focuses exclusively on EM methods, another new concept paper considers a range of multidisciplinary methods for studying Antarctic subglacial groundwater (Siegert and others, 2017).

\section{EM AND THE SUBGLACIAL ENVIRONMENT}

\subsection{Electrical conductivity}

EM mapping of groundwater exploits the differences in electrical conductivity between pore fluids and the surrounding sediments and bedrock. A key motivating factor for using EM in a glaciated environment is the large difference in conductivity between ice and groundwater. Low-impurity ice has a conductivity that is primarily governed by the slow movement of protonic point defects, resulting in a resistivity (the inverse of conductivity) of $\sim 0.4 \times 10^{5} \Omega$-m at $\sim 2{ }^{\circ} \mathrm{C}$, which increases to $4 \times 10^{5} \Omega-\mathrm{m}$ at $-58^{\circ} \mathrm{C}$ (Petrenko and Whitworth, 2002; Kulessa, 2007). The high resistivity of ice is juxtaposed with the significantly lower resistivity of groundwater, where electrical conduction is primarily an electrolytic process dominated by the concentration and mobility of ions (Kirsch, 2006). The resistivity of water strongly decreases with salinity (Perkin and Lewis, 1980). Pure deionized fresh water has a resistivity of $\sim 10^{4} \Omega-\mathrm{m}$, but the addition even small amounts of ions will greatly decrease this value. For example, water with practical salinity $<0.5$ is considered to be fresh, yet has a resistivity as low as $20 \Omega-m$ (Perkin and Lewis, 1980), over 500 times more conductive than pure fresh water (Fig. 2). Seawater at $\sim 1^{\circ} \mathrm{C}$ is $\sim 0.3 \Omega-\mathrm{m}$, and hypersaline fluids are even less resistive.

Because of its dependence on ionic content, the bulk resistivity of groundwater reflects its provenance and residence time: newly formed fresh water produced by local basal melting of clean ice will have low ion concentrations and hence high resistivity, while older mixed waters may exhibit lower resistivity due to increased ionic content from geochemical dissolution of surrounding sediments or bedrock as well as from mixing with existing saline pore fluids. Indeed, this has been the case with groundwater samples from Antartica (Fig. 2). At Subglacial Lake Whillans (SLW), located beneath Whillans Ice Stream, West Antarctica, water salinity exhibits a steep gradient in depth from a value slightly more saline than fresh water at the lake's top to brackish water less than a meter below (Michaud and others, 2016). Geochemical analysis of these samples indicates only up to a $6 \%$ contribution from 


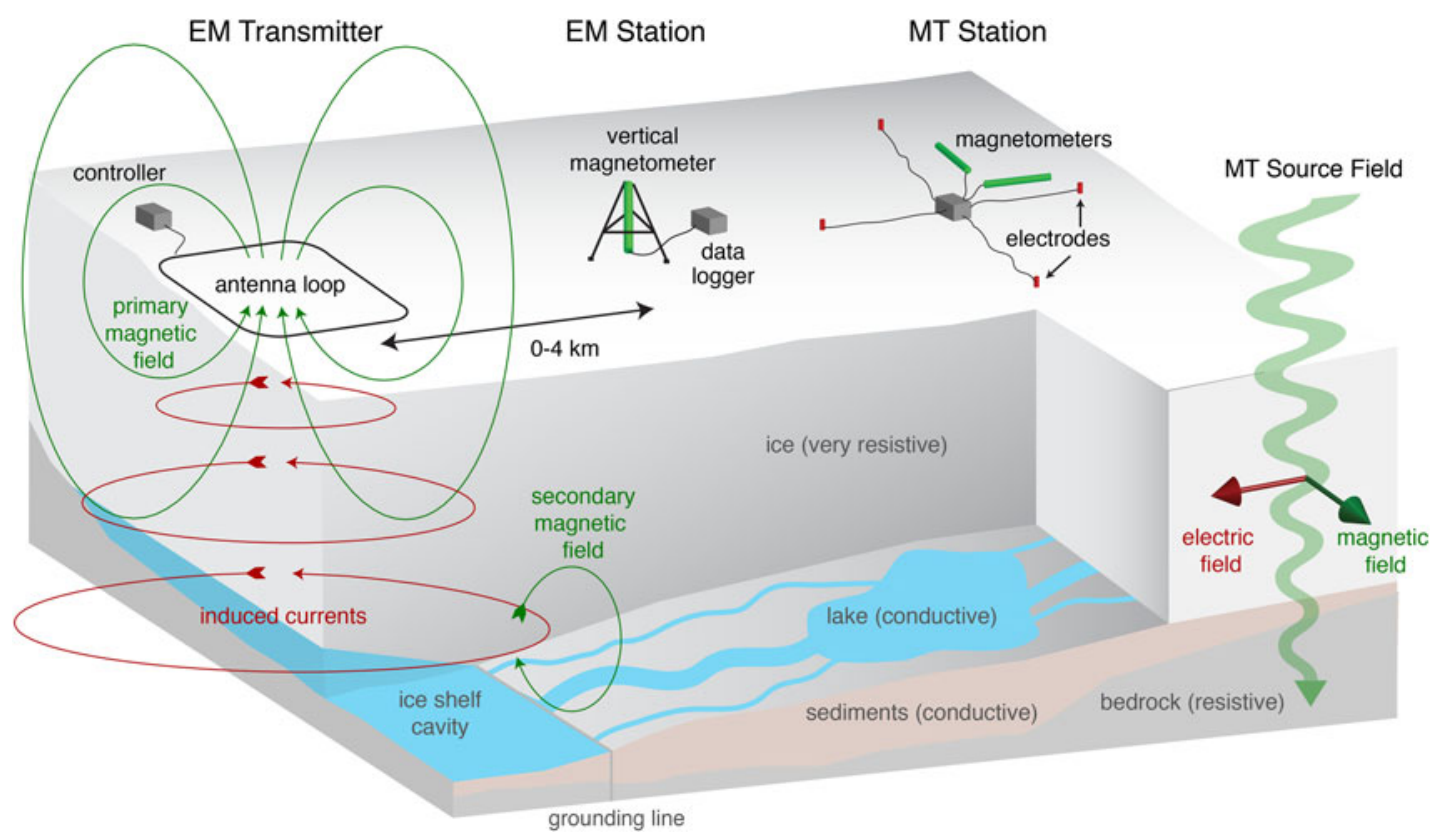

Fig. 1. Ground-based EM methods for subglacial imaging. The active-source EM method uses a transient or frequency-domain pulse of current in a large horizontal loop to induce currents in the ground. The resulting magnetic-field response function is measured at one or more receiver stations. The passive magnetotelluric (MT) method uses measurements of time variations in the naturally occurring horizontal electric and magnetic fields to estimate the frequency-dependent impedance response at a series of stations. For both techniques, the responses can be converted into electrical-conductivity models using non-linear inversion methods.

ancient seawater, and that most of the solutes arise from crustal silicate weathering from a more concentrated source at depth (Michaud and others, 2016). Samples from West Lake Bonney, a saline lake with a permanently frozen cover in Taylor Valley, show salinities ranging from brackish at shallow depths to hypersaline brines at $38 \mathrm{~m}$ depth (Spigel and Priscu, 1996). Sampling of a jökulhlaup near Casey Station, Law Dome, revealed nearly fresh outflow with low resistivity and high solute content, suggesting it had been

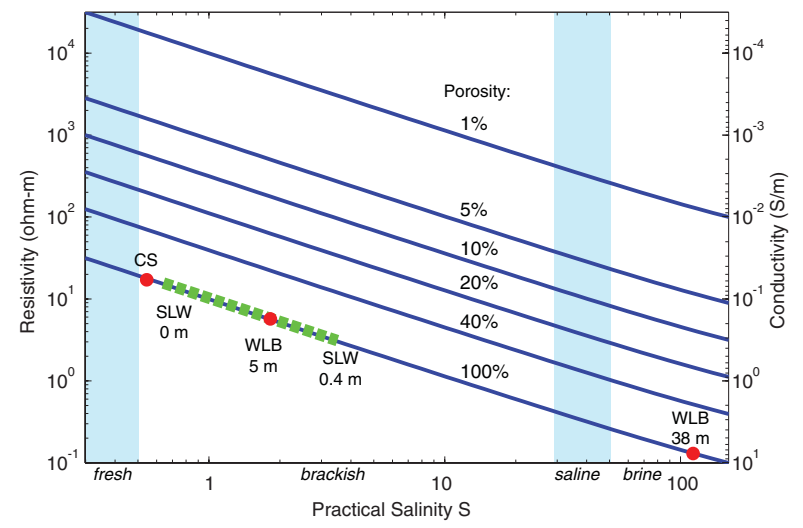

Fig. 2. Bulk electrical resistivity of sediments shown as a function of pore fluid salinity and sediment porosity. Bulk resistivity was computed using Archie's Law with exponent $m=1.5$ and temperature $0^{\circ} \mathrm{C}$. The resistivity of pore-water $(100 \%$ porosity) is from the Practical Salinity Scale 1978 (Perkin and Lewis, 1980). Red dots show direct water measurements from West Lake Bonney (WLB) at 5 and $38 \mathrm{~m}$ depth (Spigel and Priscu, 1996) and Casey Station (CS) jökulhlaup outflow (Goodwin, 1988). The dashed green line shows pore-water resistivity at Subglacial Lake Whillans (SLW) rapidly decreasing from the lake bottom to $0.4 \mathrm{~m}$ into the sediments (Christner and others, 2014; Michaud and others, 2016). For reference, the resistivity of ice greatly exceeds $10^{4} \Omega-\mathrm{m}$. squeezed through subglacial sediments for a considerable time period (Goodwin, 1988).

The bulk resistivity of water-saturated sediments, till and bedrock can be estimated using Archie's Law, an empirical formula found to work well for porous sediments (Archie, 1942) and fractured bedrock (Brace and Orange, 1968). In Figure 2, we also show the bulk resistivity for variable porosity sediments that are saturated with water of variable salinity. Resistivity decreases as porosity and salinity increase. For the minimum $1 \%$ porosity considered, the bulk resistivity is much lower than that of ice, even for salinity values considered to be fresh.

Remote characterization of the subglacial resistivity structure can therefore provide a fundamental constraint on the fluid content of the subglacial environment; for example, a wet subglacial lake or sediment package will be relatively conductive, whereas dry or frozen ground will be significantly more resistive. In addition to detecting free water in lakes beneath ice, EM data could be used to reveal groundwater systems in deeper underlying sediments and fractured bedrock, which likely has important consequences for subglacial biology and geochemical cycles (Wadham and others, 2012, 2013; Vick-Majors, 2016), and may represent a volumetrically larger component of water than the thin distributed sheets or channelized streams at the base of the ice (Christoffersen and others, 2014). Little is currently known about the deeper hydrology due to the limitations of existing geophysical data and a lack of deep borehole data in Antarctica.

\subsection{EM imaging methods}

EM geophysical techniques use low-frequency $(<10 \mathrm{kHz})$ EM induction that is governed by a vector diffusion equation (Ward and Hohmann, 1987). They have been well developed for tectonic, mineral, hydrocarbon and groundwater 
exploration (Nabighian, 1987; Kirsch, 2006; Chave and Jones, 2012). Depending on the particular technique, EM data can be preferentially sensitive to conductive features such as zones with high groundwater content, or sensitive to resistive features such as hydrocarbon reservoirs.

Because both the frequency range of EM measurements and the resistivity of the target geology can vary by orders of magnitude, the depth sensitivity of EM data can vary greatly. A measure of this is provided by the EM skin depth $Z_{\mathrm{S}}$, which is the e-folding distance of the induced field in a uniform conductor. The skin depth depends on the resistivity $\rho$ and linear frequency $f$ according to:

$$
z_{\mathrm{s}} \approx 500 \sqrt{\rho / f} \mathrm{~m}
$$

(Ward and Hohmann, 1987). For a given resistivity, the skin depth relation shows that high-frequency energy attenuates more rapidly and is sensitive to shallow structure, while low-frequency energy can penetrate more deeply. For subglacial EM imaging, high frequencies can constrain conductive water at the glacier bed but will have attenuated too much to be sensitive to deeper structure, while much lower frequencies with longer skin depths can constrain the deeper bed and basement conductivity. For example, consider a $3 \Omega-\mathrm{m}$ water body at the glacier bed. The skin depth at $10000 \mathrm{~Hz}$ is only $9 \mathrm{~m}$, while at $1 \mathrm{~Hz}$, the skin depth is $\sim 900 \mathrm{~m}$. This is contrasted by the significantly higher frequencies of radar data $(>10 \mathrm{MHz})$, which can only detect the top of a water layer since rapid attenuation within the layer limits deeper sensitivity (Schroeder and others, 2015), except in the limiting case where the water is fresh enough to have a very high resistivity and is $\sim<10 \mathrm{~m}$ thick (Gorman and Siegert, 1999; Dowdeswell and Evans, 2004). Active-source seismic data, which are governed by the wave equation, can reveal high-resolution images of subglacial geologic boundaries (Blankenship and others, 1986; Smith, 1997), but are much less sensitive to water content than EM data.

EM methods can be broadly divided into the passive magnetotelluric (MT) method and various controlled-source EM methods (Fig. 1). The MT method uses variations in naturally occurring low-frequency electric and magnetic fields to probe the electrical-conductivity structure of, typically, the crust and mantle (Chave and Jones, 2012). The source field arises from interactions of charged particles in the solar wind with the conductive ionosphere, producing stochastic time-varying currents that emanate plane-wave like pulsations down through the resistive lower atmosphere. At high frequencies $(>1 \mathrm{~Hz})$, additional source energy arises from the global distribution of lightning strikes resonating in the atmospheric cavity. This incident energy diffuses into the conducting Earth, inducing secondary electric and magnetic fields that depend on the conductivity structure.

MT data consist of time series measurements of the horizontal electric and magnetic fields at the surface, which are used to estimate a complex frequency-dependent impedance tensor that relates the electric- and magnetic-field vectors. Impedance responses measured at a series of MT stations are typically inverted using a non-linear optimization approach that solves for a conductivity model that fits the observed data. Because of the skin-depth dependence of EM fields on the frequency and resistivity, MT measurements can be used to image features on dramatically different depth scales, depending on the electrical structure and length of data acquisition. For example, recordings of weeks to months over the resistive oceanic lithosphere have been used to study partial melts in the mantle (Baba and others, 2006; Key and others, 2013; Naif and others, 2013), whereas high-frequency recordings of a day or less duration can be used to study groundwater in the shallow crust (Unsworth and others, 1999; Garcia and Jones, 2010).

Controlled-source EM soundings use a transmitter to generate the EM field. The transmitter can take the form of either a grounded dipole or a large ungrounded loop. From a theoretical point of view, the grounded dipole source is preferred since it produces both transverse electric (TE) and transverse magnetic (TM) polarization modes of the EM field, and thus has a richer structural sensitivity than a loop source, which only generates the TE mode (Chave and Cox, 1982; Ward and Hohmann, 1987). However, since the signal-to-noise ratio of EM data is directly proportional to the current in the transmitter wire, the large loop method is often preferred in areas where high ground contact resistance (e.g. ice, bedrock, or extremely dry cover) severely limits the amount of current that can be injected with a grounded dipole. Further, loop sources can also be mobilized, for example, for highly efficient airborne EM surveys (Christiansen and others, 2006). Because they only generate the TE mode, loop sources create EM fields that are preferentially sensitive to conductive features.

The loop source creates a large magnetic dipole field that is pulsed in time, inducing eddy currents in the subsurface that in turn create secondary magnetic fields. The resulting total magnetic field at the surface is measured at one or more receiver stations. Since this controlled-source EM method can generate a much stronger source field than the natural MT fields and since electric fields do not need to be measured, surveys can often be acquired rapidly. Data acquisition can use a time domain or frequency domain approach. In the time-domain approach known as the transient EM (TEM) method, the transmitter current is rapidly turned off and the resulting transient pulse is recorded (Christiansen and others, 2006). For TEM soundings, the response at early times gives shallow sensitivity, while the response at late times gives deeper depth sensitivity. Conversely, measurements can be made in the frequency domain using a periodic transmitter waveform with the EM responses computed at the various waveform harmonics. Here, we will refer to frequency domain EM as FDEM.

One of the fundamental differences between TEM and FDEM is the ability to record measurements coincident with the loop source. Close to the source, the primary magnetic field generated by the loop can be many orders of magnitude larger than the secondary field. Thus, FDEM measurements, which record the superposition of both fields, can have low sensitivity to the secondary field close to the source. Conversely, TEM measurements can be made close to the source since the primary field travels through the air and rapidly propagates away during early times after the current is turned off, whereas the secondaryfield transient arising from the ground response travels more slowly and appears at later times. Thus, TEM measurements tend to be made with receivers located within or next to the loop source, whereas FDEM measurements tend to be made with receivers at a distance from the source where the induced secondary-field strength is of similar order to the primary field. 


\subsection{Previous EM surveys in Antarctica}

Early MT surveys in Antarctica include low-frequency measurements of the telluric current at Vostok Station (Hessler and Jacobs, 1966) and reports mentioning MT data collected at Dome C (Bentley and others, 1979; Shabtaie and others, 1980). Beblo and Liebig (1990) present the first quantitative analysis of Antarctic MT data, describing a suite of four stations collected on Priestly Glacier, North Victoria Land, with encouraging results for investigating sub-ice sedimentary basins. More recent studies have concentrated on using low-frequency MT data to study deep crustal and upper mantle tectonics (Wannamaker and others, 1996, 2004, 2012; Peacock and Selway, 2016). Although theoretical considerations suggest that departures from the MT plane-wave source-field assumption may be prevalent at the poles due to the presence of the polar atmospheric electrojets (Pirjola, 1998), Beblo and Liebig (1990) showed that MT impedance responses from different time segments remain stationary despite clear variations in source strength associated with the electrojet. This conclusion is also supported by the lack of source-effect complications in more recent datasets (Wannamaker and others, 1996, 2004; Peacock and Selway, 2016).

The use of controlled-source EM methods in Antarctica has been very limited. Ruotoistenmäki and Lehtimäki (1997) report on a pioneering use of FDEM to map saline brines beneath continental ice and permafrost in western Dronning Maud Land, where they mapped the depth to a subglacial conductive layer along a $35 \mathrm{~km}$ transect. Their multifrequency system collected data at 2-20 $000 \mathrm{~Hz}$ with source-receiver offsets up to $1500 \mathrm{~m}$. Where the ice was $<650 \mathrm{~m}$ thick, their system found 20-500 $\Omega-\mathrm{m}$ subglacial conductors that they attributed to saline brines. A more recent exception is the groundbreaking use of helicopterbased TEM surveying carried out in 2011-2012 to map shallow groundwater in the McMurdo Dry Valleys, East Antarctica. This dataset has revealed laterally extensive zones of conductive groundwater throughout the Dry Valleys, including a confined aquifer beneath Lake Vida (Dugan and others, 2015) and conductive groundwater confined beneath the lower extent of Taylor Glacier, which may extend far upstream (Foley and others, 2015; Mikucki and others, 2015). This recent EM-based discovery of extensive groundwater, despite an abundance of previous non-EM studies in this region, illustrates that controlled-source EM techniques are practical for glaciological applications and provide a unique physical constraint on subglacial water that cannot be collected through more conventional glaciophysical methods. The direct current resistivity technique, which is a controlled-source electrostatic method governed by a Poisson equation (and thus has lower resolution than diffusive EM methods), has been used to study ice properties at a few locations throughout Antarctica (Hochstein, 1967; Bentley, 1977; Reynolds and Paren, 1984; Shabtaie and Bentley, 1994).

\subsection{Potential application of high-frequency EM methods under thick ice}

Passive-source MT surveying in Antarctica is now an established technique, with validated methods for implementation on ice (e.g. Wannamaker and others, 2004). In contrast to the existing lower frequency applications of MT for investigating tectonic questions, the model studies we present below show that higher frequency data collected in the audio-frequency range are highly sensitive to the shallower depths of subglacial groundwater, and thus MT data could play a principal role in future field efforts to remotely quantify subglacial groundwater. From an observational standpoint, groundwater is an entirely unknown quantity beneath the ice sheet in Antarctica, yet initial model estimates from the Siple Coast indicate that it represents a significant fraction of the total subglacial water budget as well as a potential unquantified habitat for subglacial microbial life (Christoffersen and others, 2014).

Controlled-source EM surveying has much more limited use in Antarctica, yet an initial airborne pilot study in the Dry Valleys, East Antarctica, has produced transformative results (Dugan and others, 2015; Foley and others, 2015; Mikucki and others, 2015). While airborne EM similar to the Dry Valleys study has unrivaled efficiency for spatial coverage, its application is not suited to the ice-sheet interior as the system is unable to map conductivity beneath more than $\sim 400$ m ice thickness; a further limitation is that the penetration of the TEM field into conductive subglacial sediments is limited to $\sim 100 \mathrm{~m}$ or less, and so airborne EM data are unable to map any deeper groundwater in sediments or porous bedrock. Ground-based controlled-source EM surveying can collect data with a much higher signal-to-noise ratio, made possible through a significantly larger transmitter dipole moment as well as much longer data stacking times and thus holds potential for subglacial groundwater mapping.

EM data also may be well suited for mapping subglacial permafrost regions since they would have much higher resistivity than wet unfrozen sediments; Siegert and others (2017) includes a model study showing how MT data could be used to image permafrost hypothesized beneath the Bungenstock Ice Rise and wet sediments hypothesized beneath the adjacent Institute Ice Stream. Although EM methods are typically used to create a single image of ground conductivity, campaign-style time-lapse EM surveys or continuous monitoring systems could be used to constrain the dynamic components of groundwater and interfacial systems. Because future applications of EM for cryospheric studies have strong potential for transformative new discoveries, in the remainder of this work, we investigate the utility of ground-based MT and controlled-source EM methods for subglacial characterization.

\section{ONE-DIMENSIONAL (1D) SENSITIVITY STUDIES}

To assess the viability of ground-based EM methods for observing a range of subglacial hydrological features, here we develop a suite of synthetic modeling studies. We begin with 1D model simulations that characterize the sensitivity of MT, FDEM and TEM data to thin layers of variable conductivity. These studies center around a simple 1D model consisting of $1000 \mathrm{~m}$ of ice overlying a $10 \Omega-\mathrm{m}$ conductive layer of variable thickness that is representative of either a subglacial lake with a salinity of 1.0 or wet sediments. Given the trade-offs that porosity and salinity have on bulk resistivity, $10 \Omega-\mathrm{m}$ could represent a range of wet sediment conditions; for example, $20 \%$ porosity sediments with water salinity 15 , or a much lower porosity of $5 \%$ with a much higher salinity of 200 . The model is terminated with a $500 \Omega-\mathrm{m}$ (resistive) basement layer. EM responses are computed using freely available 1D EM forward modeling codes (Key, 2012). 


\subsection{MT sensitivity}

For a $1 \mathrm{D}$ model, the MT response can be characterized using a single station located on the ice surface. Figure 3 shows the MT apparent resistivity and phase responses for a conductive wet subglacial layer with thickness ranging from 0 to $1000 \mathrm{~m}$. The MT responses show a significant departure from the response of the base model, which has no conductive layer $(0 \mathrm{~m})$, with the thickest conductive layer response showing the largest signal in both the apparent resistivity and phase responses. This result clearly demonstrates that MT data need to be acquired in the frequency range of 0.01-1000 $\mathrm{Hz}$ in order to detect the conductive layer and constrain its layer thickness.

In Figure 4, we expand this study to show the anomaly in the MT apparent resistivity for a range of wet layer thicknesses and resistivities. The anomaly is shown on a relative scale by differencing the responses for models with and without the wet layer, and then normalizing this difference by the wet model response. We computed the relative anomaly at frequencies from 0.001 to $10000 \mathrm{~Hz}$. Figure 4 shows the maximum anomaly over all frequencies as a function of wet layer thickness and resistivity. We can use this result to determine whether a given layer thickness and resistivity could be detected by MT measurements. For example, it shows that when the ice is $4000 \mathrm{~m}$ thick, $10 \mathrm{~m}$ thick wet sediments with $1 \Omega$-m resistivity will give a $100 \%$ anomaly. We also see the well-known equivalence for MT responses from thin deeply buried conductive layers, which are primarily sensitive to the conductivity-thickness product of the layer. For example, a $1 \mathrm{~m}$ thick layer with $0.1 \Omega$-m resistivity produces the same response anomaly as $100 \mathrm{~m}$ thick $10 \Omega$-m layer.

The response anomaly also shows a dependence on the thickness of the overlying ice layer, with thinner ice having a stronger anomaly than thicker ice; therefore, subglacial conductive layers will be easier to detect when the ice is thinner. Since high-quality MT data will generally have uncertainties that are $\sim<1-10 \%$, the overall ability to detect subglacial conductive layers looks quite good for the range of ice thicknesses found in polar regions. For example, if $10 \%$ is determined to be the safe cutoff level for target detectability, then MT could detect a $10 \Omega-\mathrm{m}$ layer that is $1 \mathrm{~m}$ or thicker when located beneath $500 \mathrm{~m}$ of
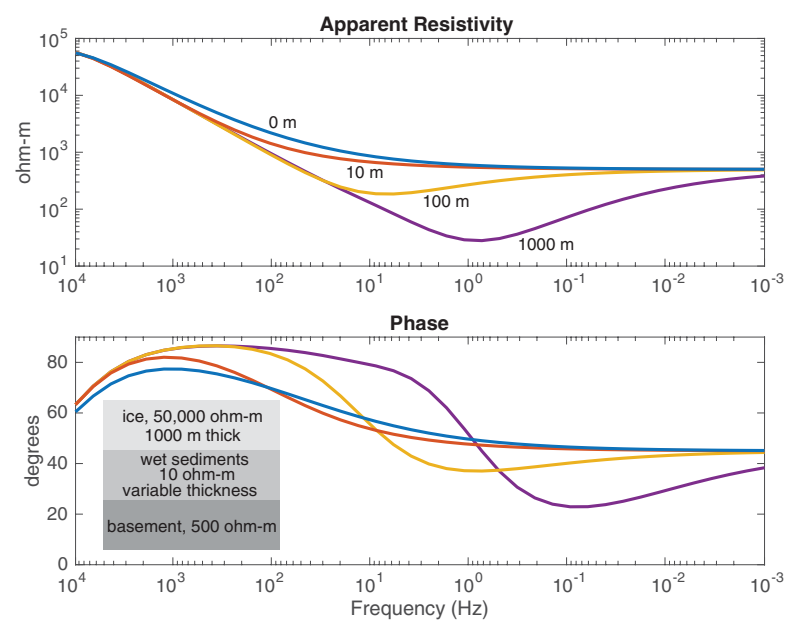

Fig. 3. Effect of a subglacial conductive layer on the MT response for a $1 \mathrm{D}$ model with $1000 \mathrm{~m}$ thick resistive ice overlying $10 \Omega$-m wet sediments of variable thickness, as indicated by the labeled curves. ice, or $10 \mathrm{~m}$ or thicker when located beneath $4000 \mathrm{~m}$ of ice. We conclude that MT data will be useful for detecting subglacial water for a wide range subglacial layer thicknesses and resistivities.

We also examined the effect that variable ice resistivity could have on the MT responses (Fig. 5). Variable ice resistivity primarily affects the high-frequency part of the response above $1000 \mathrm{~Hz}$, and therefore ice resistivity variations will have negligible effect on the $0.01-1000 \mathrm{~Hz}$ window where the sensitivity to subglacial conductive layers is greatest. While our focus here is primarily on subglacial imaging, this example demonstrates that MT data at frequencies above $1000 \mathrm{~Hz}$ could be useful for studying the physical properties of the overlying ice.

\subsection{FDEM sensitivity}

Here, we test the sensitivity of FDEM methods to subglacial conductive features with the same simple 1D model used for the MT study in the previous section. Since the FDEM response varies as a function of distance, we model the forward response at various source-receiver offsets. We use this synthetic study to determine the most important frequency bands and offsets at which FDEM data are preferentially sensitive to subglacial conductivity anomalies.

Similar to MT, FDEM shows the best sensitivity to the conductive layer thickness within the $0.1-1000 \mathrm{~Hz}$ window (Fig. 6). These results show that data at increasingly lower frequencies are required as the layer thickness increases. For example, data in the $1-50 \mathrm{~Hz}$ band need to be obtained to discriminate the responses for 100 and $1000 \mathrm{~m}$ thick conductive layers.

The sensitivity of FDEM to layer thickness increases with offset, suggesting long-offset FDEM surveys will provide the best estimate of subglacial conductivity structure. However, the amplitude of the FDEM signal diminishes rapidly with increasing offset, and so the feasibility of obtaining low-amplitude measurements must be considered. The noise level of the measurement will depend on noise generated by the magnetic-field sensor as well any ambient magnetic-field noise, for example, from cultural sources and the naturally occurring MT field. Here, we assume that the measurements are made with highly sensitive induction coil sensors designed to measure the MT magnetic-field components (Nichols and others, 1988), so that the sensor noise is negligible. Cultural EM noise is likely to not be an issue in remote glaciological locations of interest. Therefore, the noise will be dominated by MT signals, which we estimate with the vertical magnetic-field spectrum $B_{\mathrm{MT}}(f)$. The estimated noise level for a FDEM measurement is then found by normalizing $B_{\mathrm{MT}}(f)$ by the effective stacking moment $M$ of the transmitter source, giving the effective FDEM response noise level

$$
B_{\text {noise }}(f)=\frac{B_{\mathrm{MT}}(f)}{M},
$$

where

$$
M=n I A \sqrt{N}
$$

$n$ is the number of turns in the transmitter loop, $I$ is the current in the loop, $A$ is the loop area and $N$ is the stack window length in seconds. $M=10^{6}$ could be obtained, for example, with a single square wire loop $(n=1)$ with side 

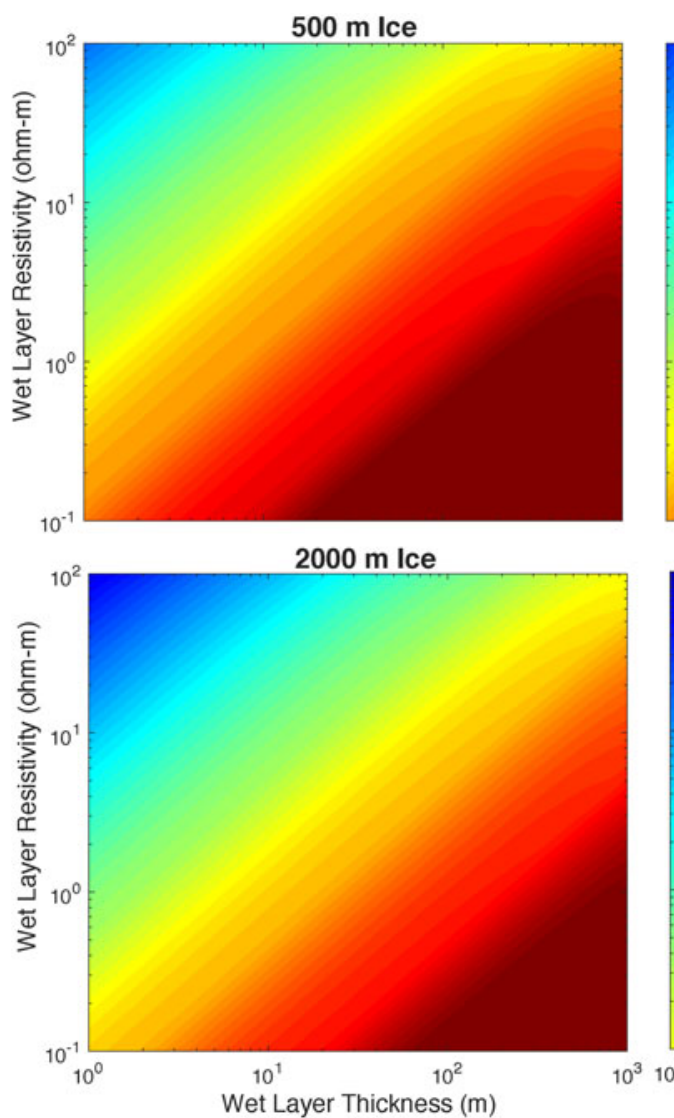

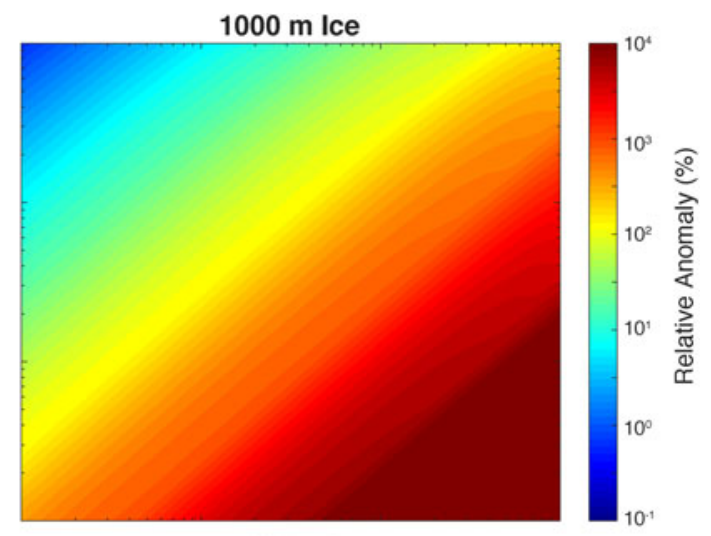

$4000 \mathrm{~m}$ Ice

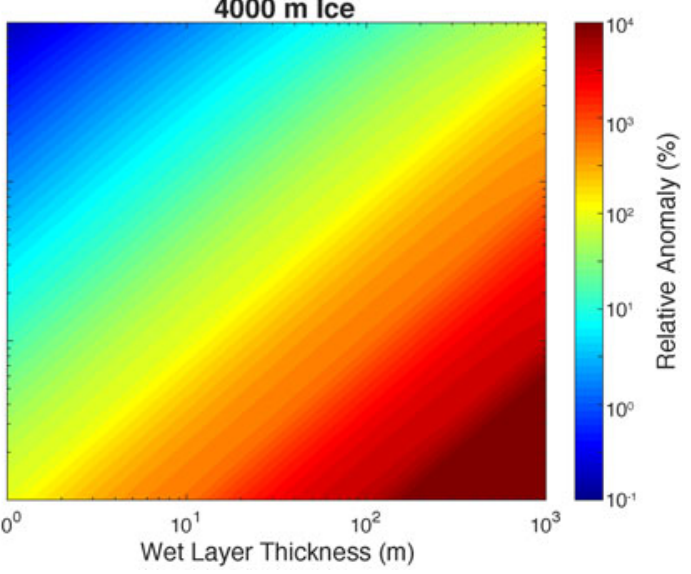

Fig. 4. Relative anomaly in the MT apparent resistivity response for a model with a conductive wet layer shown as a function of the layer resistivity and thickness. The anomaly is computed as the maximum relative difference between the response of the wet layer model and the response from a model without the wet layer. The maximum relative difference was computed in the frequency band $0.001-10000 \mathrm{~Hz}$ and is shown for four different ice thicknesses (500, 1000, 2000 and $4000 \mathrm{~m}$ ).

length $400 \mathrm{~m}$, a transmitter current of just over $6 \mathrm{~A}$ and a stacking window $N=1 \mathrm{~s}$. These parameters are well within the capabilities of currently available FDEM instrumentation. It is also worth noting that the same moment could be obtained with different combinations of these parameters, depending on their suitability for the FDEM transmitter system as well as their suitability for efficient field operations.
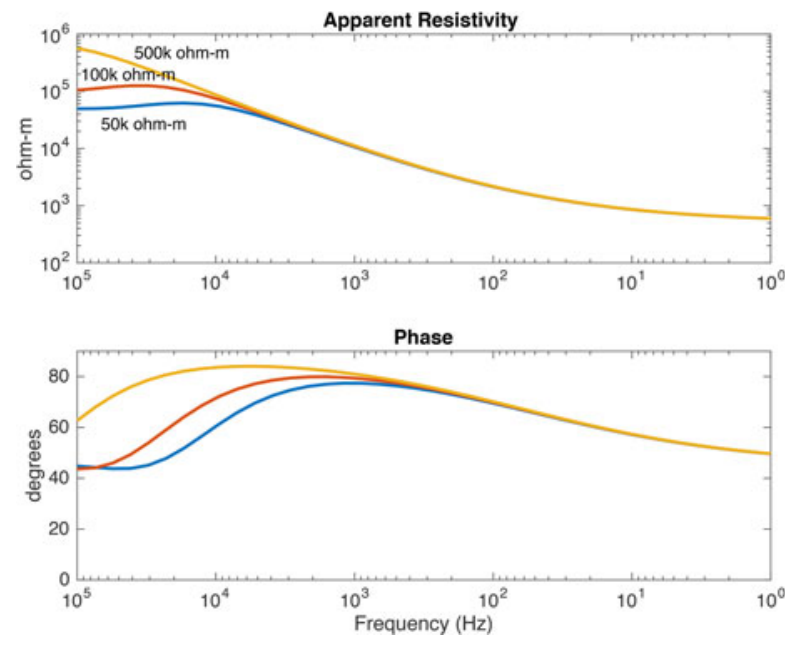

Fig. 5. Effect of ice resistivity on the MT impedance response for a 1D model with $1000 \mathrm{~m}$ thick ice overlying a $500 \Omega$-m halfspace. The variable ice resistivity affects only the high-frequency portion of the response.
Figure 6 shows $B_{\text {noise }}$ estimated using measurements of the vertical magnetic field we collected over resistive ground in the Mojave Desert in March 2015 and assuming $M=10^{6}$ and $10^{7} \mathrm{Am}^{2} \sqrt{\mathrm{s}}$. At $2 \mathrm{~km}$ offset, the signal from the conductive layer is well above both estimated noise levels, whereas the response at 4 and $6 \mathrm{~km}$ offset is limited by the $M=10^{6}$ noise level at frequencies below $2 \mathrm{~Hz}$ at $4 \mathrm{~km}$ offset and below $20 \mathrm{~Hz}$ at $6 \mathrm{~km}$ offset. Despite this, high sensitivity is possible at higher frequencies and shorter offsets. We conclude that FDEM measurements sensitive to subglacial groundwater could be made with high signal-to-noise ratio in general. Further noise reduction may be possible by using one or more remotely located stations (i.e. $8 \mathrm{~km}$ or more from the transmitter); with these stations, the spatially coherent MT source field can be estimated and removed from the FDEM data, yielding lower noise levels than those shown in Figure 6.

In Figure 7, we expand the FDEM study to look at the sensitivity to a conductive subglacial layer as a function of its resistivity as well as thickness. In a similar manner to the MT study in the previous section, we generate FDEM responses over a range of layer thicknesses and resistivities and show the maximum relative anomaly for all frequencies and receiver offsets. The FDEM data, like MT data, exhibit equivalent response anomalies for a given conductivitythickness product of the subglacial layer. Comparison of Figures 7 and 4 shows that for a given model, the FDEM response anomaly is generally much smaller than the MT anomaly. The FDEM anomaly also decreases more rapidly 

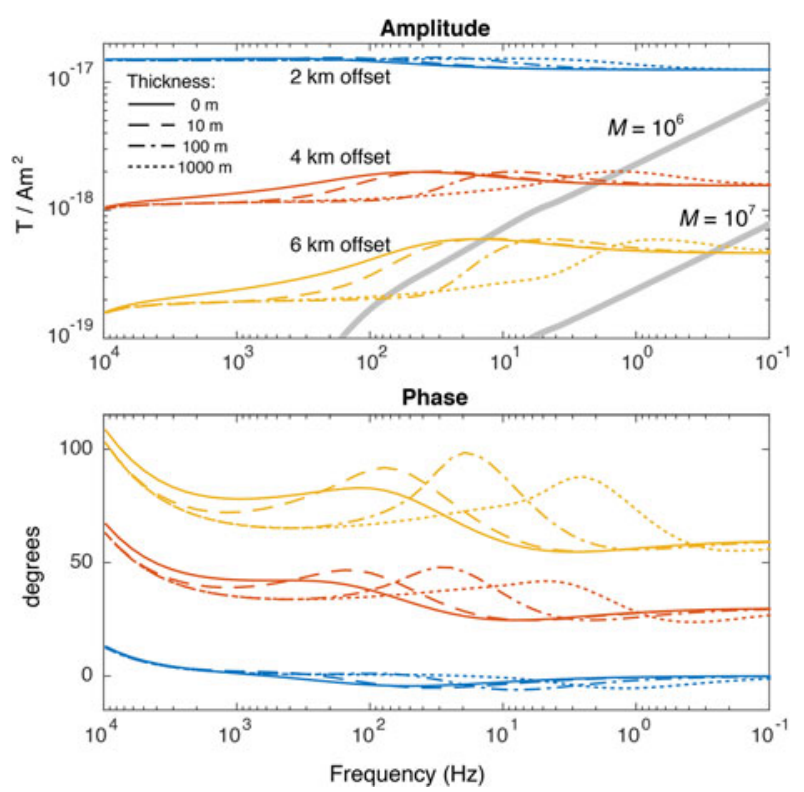

Fig. 6. FDEM responses for the test model shown as a function of frequency at various offsets from the transmitter loop. The various thin colored lines show the responses as a function of conductive layer thickness. Phase values for 4 and $6 \mathrm{~km}$ offsets have been shifted by 30 and $60^{\circ}$ for visual clarity. Thick gray lines show approximate vertical magnetic-field noise levels $B_{\text {noise }}$ for two stacking moments. See text for further discussion of the noise levels. as the ice thickness increases. For example, the FDEM anomaly for a given layer resistivity and thickness is about ten times smaller for $4000 \mathrm{~m}$ ice than for $1000 \mathrm{~m}$ ice, whereas the MT anomaly is only about three times smaller. While these studies suggest that FDEM is less sensitive to subglacial layers, particularly when the ice is thicker than $1 \mathrm{~km}$, the practical sensitivity for field data will also depend on the fidelity and uncertainty in the measurement. Since FDEM can be collected using powerful transmitter antennas and long data stacking windows, it may be possible to obtain FDEM data with significantly smaller data uncertainties than possible for passive MT data; in such a case, the relative differences in sensitivity could be offset by the decreased uncertainty in FDEM data.

\subsection{TEM sensitivity}

Here, we examine the sensitivity of TEM data to a subglacial conductive layer. Since a significant benefit of TEM measurements is the ability to make measurements coincident with the transmitter, we will only consider the TEM response at zero offset from the transmitter where the signal strength will be largest. Figure 8 shows that data in the time band of $10^{-5} \mathrm{~s}$ to at least $10^{-2} \mathrm{~s}$ show the strongest sensitivity. As the layer becomes thicker, the TEM responses at early times remain identical until some critical time-offset that depends on the layer thickness. Further, the amplitude of
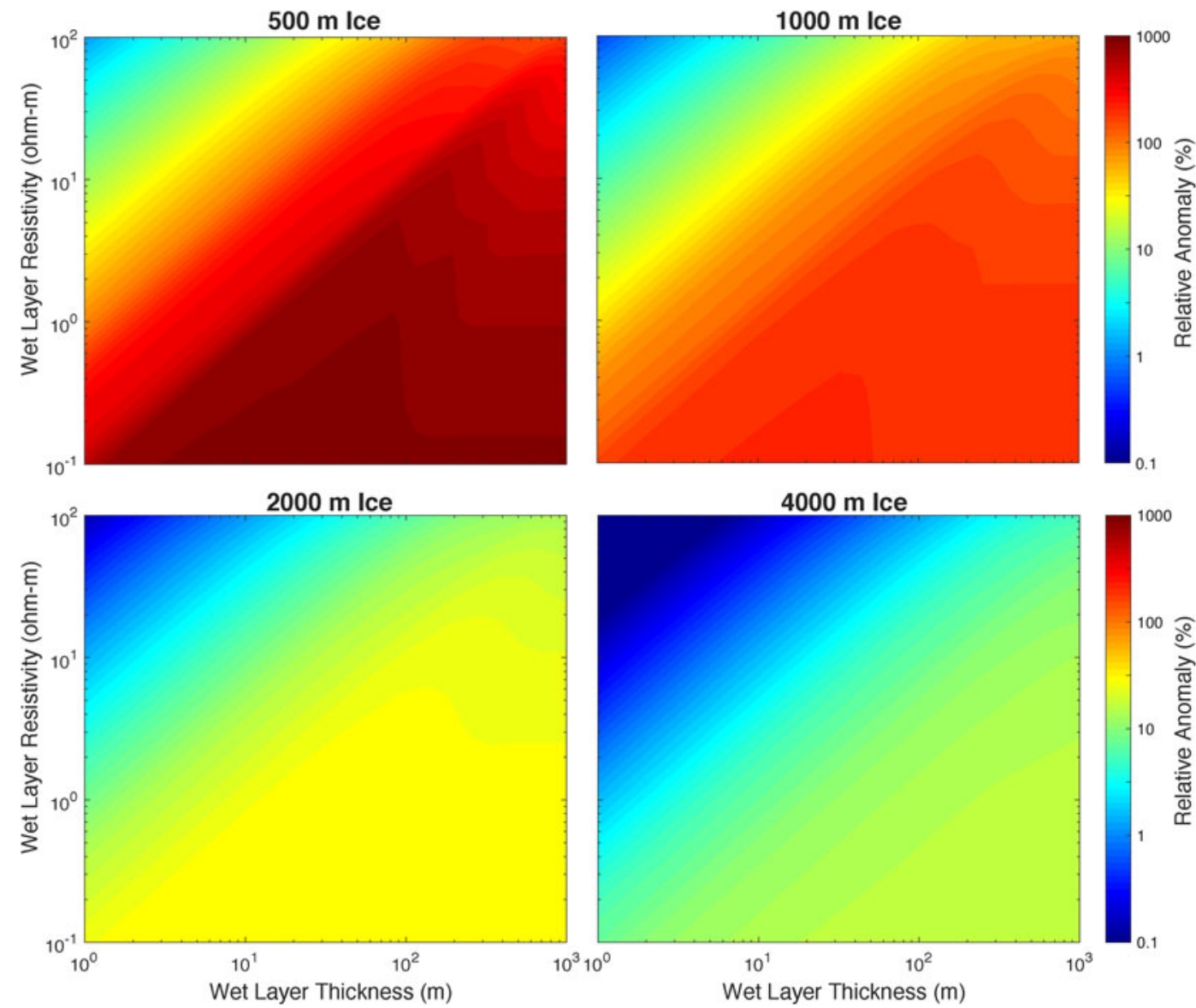

Fig. 7. Relative anomaly in the FDEM response for a model with a conductive wet layer shown as a function of variable layer resistivity and thickness. The anomaly is computed as the maximum relative difference between the response of the wet layer model and the response from a model without the wet layer. The maximum relative difference was computed in the frequency band $0.1-10000 \mathrm{~Hz}$ at offsets from 2 to $6 \mathrm{~km}$ and is shown for four different ice thicknesses (500, 1000, 2000 and $4000 \mathrm{~m}$ ). 


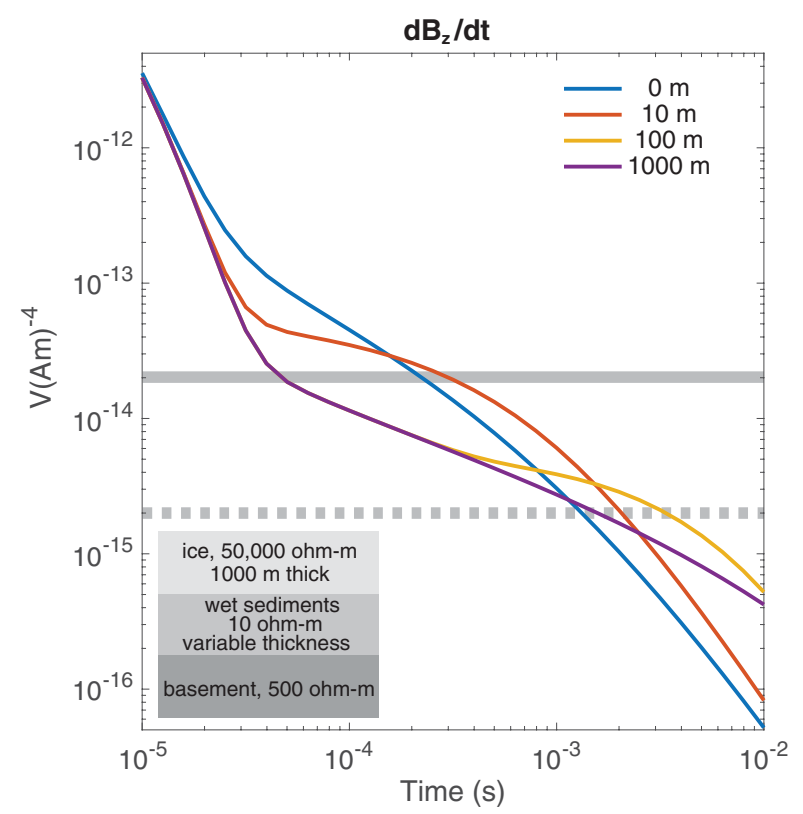

Fig. 8. TEM responses for the test model shown for various conductive layer thicknesses. The solid gray line shows the approximate noise level of data obtained by an airborne EM survey in Antarctica (Dugan and others, 2015; Foley and others, 2015; Mikucki and others, 2015). The dashed gray line shows a hypothetical noise floor for a ground-based system with an order of magnitude larger dipole stacking moment $M$, which is possible by increasing the loop diameter, source current and the data stacking window length.

the signal diminishes greatly as the conductive layer thickens. For the overlying $1000 \mathrm{~m}$ thick ice layer used in this study, the ability to detect a thin subglacial conductive layer with the airborne EM system previously used in Antarctica would be very difficult since most of the differentiating signal in the response is below the system noise level (solid gray line in Fig. 8). However, the diameter of the loop for that system is only $\sim 22 \mathrm{~m}$ due to the necessity of flying it from a helicopter; it is possible that much greater loop diameters could be used with a ground-based system, so that the different responses of the conductive channel could be measured. For example, a loop with an order of magnitude larger area would result in a noise floor ten times smaller than the airborne EM system and would likely yield useful data (dashed gray line in Fig. 8). Likewise, a lower noise floor may be possible by using much longer data stacking times with a stationary ground-based antenna. Although we do not further consider TEM data in this study, this example suggests that ground-based TEM soundings made with powerful antennas could also be useful for mapping subglacial conductivity beneath thick ice.

\section{SYNTHETIC 2D INVERSION STUDIES}

The previous section demonstrated the sensitivity of EM data to conductive subglacial water layers. Here, we examine how well EM data can image subglacial hydrology by carrying out a suite of $2 \mathrm{D}$ inversion studies using synthetic data. Our methodology follows a four-step process: (1) we design an idealized ice-water-rock model geometry and assign conductivities to each region; (2) we then create a set of a receiver stations on the surface and determine the synthetic EM responses to the geometry at each receiving station using a 2D modeling code; (3) we add realistic
Gaussian noise to the synthetic responses in order to mimic real survey data; and (4) we invert the synthetic data, so that we can compare the inversion's structure with the true model.

\subsection{Subglacial lake study}

We perform our first synthetic modeling study on a realistic lake geometry based on SLW, a shallow, active subglacial lake beneath Whillans Ice Stream, West Antarctica (Fricker and others, 2007). We also added a hypothetical deeper underlying groundwater geometry. The model (Fig. 9a) consists of an $800 \mathrm{~m}$ thick ice sheet, underlain by a moderate porosity, saturated sediment (100 $\Omega-\mathrm{m})$, underlain by a low porosity, drier sediment or fractured igneous basement (1000 $\Omega-\mathrm{m})$. The saturated sediment layer thickens from 50 to $300 \mathrm{~m}$ over the domain, to test the ability for EM methods to retrieve near-surface sedimentary structures with the potential for groundwater flow. In the center of the domain, there is a $2 \mathrm{~km}$ wide, $5 \mathrm{~m}$ thick and $3 \Omega$-m subglacial lake. Receiver stations are placed at $500 \mathrm{~m}$ spacing from -2 to $4 \mathrm{~km}$ position on the ice surface. For the FDEM data, transmitters are spaced every $1 \mathrm{~km}$.

We chose SLW as the inspiration for our test model as SLW is small relative to other nearby active subglacial lakes (Fricker and others, 2007; Fricker and Scambos, 2009; Siegfried and others, 2014, 2016) and contains fresh to brackish water. This domain therefore represents a small and difficult target for EM methods, compared with bigger, potentially more consequential nearby subglacial lakes, as well as compared with grounding zone domains, where the higher conductivity of inflowing seawater $(0.3 \Omega-\mathrm{m})$ will produce a larger EM response. The SLW area was also the subject of active seismic and radio-echo sounding surveys (Christianson and others, 2012; Horgan and others, 2012) and was directly sampled as part of the Whillans Ice Stream Subglacial Access Research Drilling project (Tulaczyk and others, 2014). We use this additional information to examine the impact of additional constraints on our inversion for subglacial conductivity structure.

We compute synthetic EM responses for each receiver station using MARE2DEM, a freely available, parallel-adaptive, finite-element modeling code (Key and Ovall, 2011; Key, 2016). Since MARE2DEM does not support TEM inversion with large loop sources and there are no freely available 2D TEM inversion codes, here we only consider MT and FDEM data. The MT data are computed at 21 frequencies logarithmically spaced from 0.1 to $1000 \mathrm{~Hz}$, and FDEM data are computed at seven frequencies from 1 to $1000 \mathrm{~Hz}$. Synthetic data are generated by adding 1\% random Gaussian noise to the EM responses. We then use MARE2DEM for the nonlinear inversion of the synthetic responses; in order to stabilize the inverse problem, the inversion seeks to find a smooth resistivity model (i.e. minimizing the spatial gradient of the conductivity structure) that fits the data. For all the inversions shown here, we use a uniform $1 \Omega$-m half-space as the starting model and the inversions are run until converging to a rootmean-square misfit of 1.0. Since the ice thickness is generally well known (e.g. from radar soundings or seismic imaging), in our inversions, we held the ice as fixed structure and only inverted for the subglacial conductivity. We test both unconstrained inversions, where we have no additional information, and constrained inversions, for the case where we have 
a

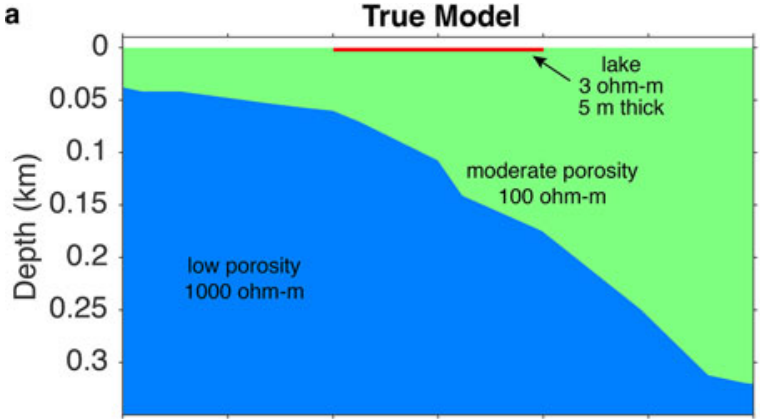

C

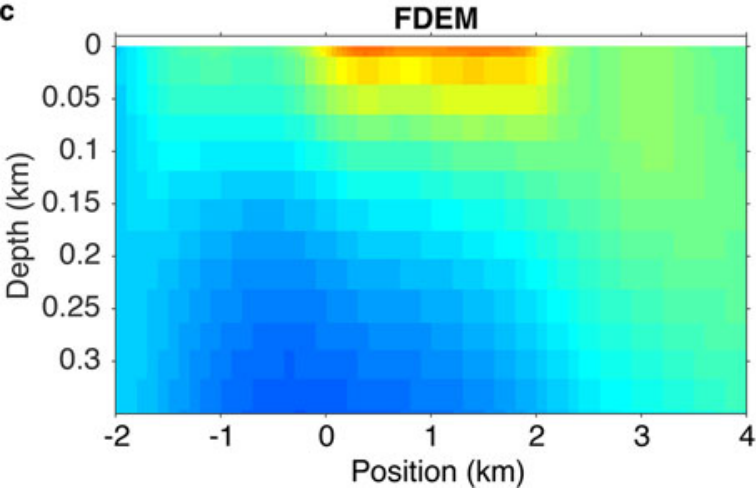

b

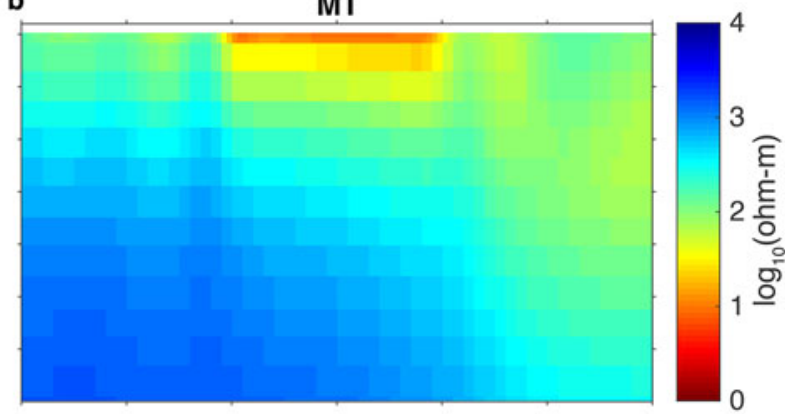

d

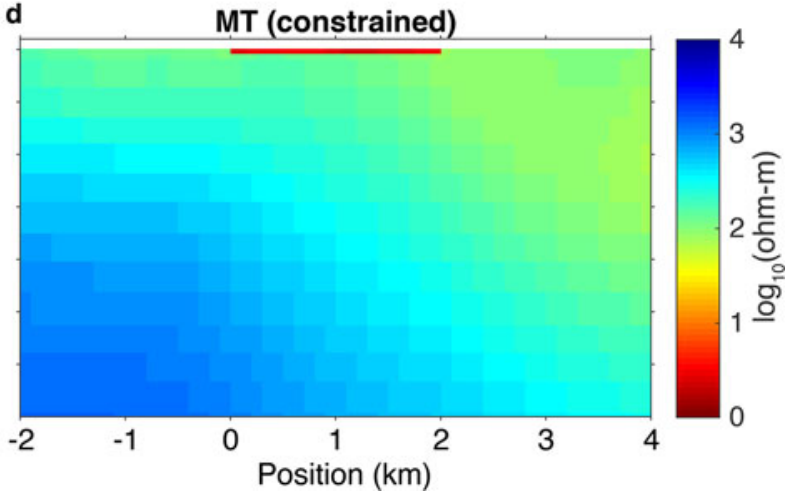

Fig. 9. Synthetic 2D inversion tests for imaging a subglacial lake and deeper sedimentary structure. (a) True model electrical resistivity structure. Only the lower subglacial portion of the model is shown; the full model includes an overlying uniform ice layer that is $800 \mathrm{~m}$ thick with resistivity $50000 \Omega$-m. Receivers are positioned every $500 \mathrm{~m}$ across the ice surface. Panels (b) and (c) show unconstrained smooth inversions of synthetic MT and FDEM data, while (d) shows a constrained MT inversion where the inversion's smoothness constraint was relaxed along the base and sides of the lake structure.

additional information on structural boundaries from other geophysical methods.

The unconstrained smooth inversions of MT (Fig. 9b) and FDEM (Fig. 9c) data recover the lateral position of the lake, the thickening trend of the underlying sediments and the high basement resistivity. For buried thin conductors, MT and FDEM data best constrain the total conductance (the conductivity-thickness product), and hence unconstrained inversion models tend to overestimate the thickness and underestimate the conductivity due to the smoothness constraint of the inversion method. If the thickness can be independently constrained, for example, from seismic or borehole data, then a constrained MT inversion can be used to more accurately recover conductivity, or viceversa. Figure $9 \mathrm{~d}$ shows an example where the lake thickness was constrained to the true value $(5 \mathrm{~m})$. This was implemented by relaxing the inversion's smoothness constraint along the lake boundaries. The inversion recovers nearly the true conductivity of the subglacial lake ( $3 \Omega-\mathrm{m})$, while retrieving the background sedimentary conductivity with higher fidelity compared with the unconstrained model (Fig. 10). Thus, the combination of a method that preferentially retrieves geologic structure (e.g. active seismic surveying) with EM methods, which preferentially retrieve conductivity structure, can provide a significantly improved understanding of the subglacial environment than either method individually. Similar constraints could be applied to the FDEM inversion and the outcome would likely be similar to the constrained MT inversion.

While these inversion examples demonstrate that EM methods can constrain a subglacial lake in $2 \mathrm{D}$, it is also worthwhile to look at some of the EM responses that formed the data for the inversions. Figure 11 shows example MT responses for a station over the middle of the lake for the SLW-like domain and for the same domain with the lake removed from the initial geometry. This experiment demonstrates that MT data for both the TE (electric currents parallel to the $2 \mathrm{D}$ strike) and TM (electric currents perpendicular to the $2 \mathrm{D}$ strike) polarization modes in the frequency band from 0.1 to $1000 \mathrm{~Hz}$ will be important for imaging the subglacial electrical structure. Both modes show large differences between the lake and dry models, with the TE mode having a broad localized low apparent resistivity anomaly centered $\sim 50 \mathrm{~Hz}$, which is similar in appearance to the 1D MT responses shown in Figure 3. The TM mode apparent resistivity also is lower for the lake model, but reaches an asymptote (i.e. apparent resistivity becomes frequency independent) that persists to the lowest frequency considered $(0.1 \mathrm{~Hz})$; this is likely due to the effect of static boundary charges on the lateral edges of the conductive lake. The $100 \%$ variation in the MT responses between the wet and dry models is much larger than the signal produced by other targets that MT is commonly used to image, and critically is much larger than the $\sim 1 \%$ noise level we expect for real MT data; even if unexpectedly adverse field conditions produce a higher noise level of, for example, $10 \%$, the MT data would be still able to constrain porosity and water content variations.

Figure 12 shows example FDEM responses at 2, 4 and $6 \mathrm{~km}$ offset centered over the lake. Despite the 2D lake geometry, these responses are qualitatively similar in magnitude and frequency behavior to the 1D responses shown in Figure 6. The largest anomaly between the dry and wet models occurs $\sim 100 \mathrm{~Hz}$ with differences of up to $30 \%$ in amplitude and $6^{\circ}$ phase at both 4 and $6 \mathrm{~km}$ offsets, while much smaller anomalies are seen at $2 \mathrm{~km}$ offset. The magnitude of these 


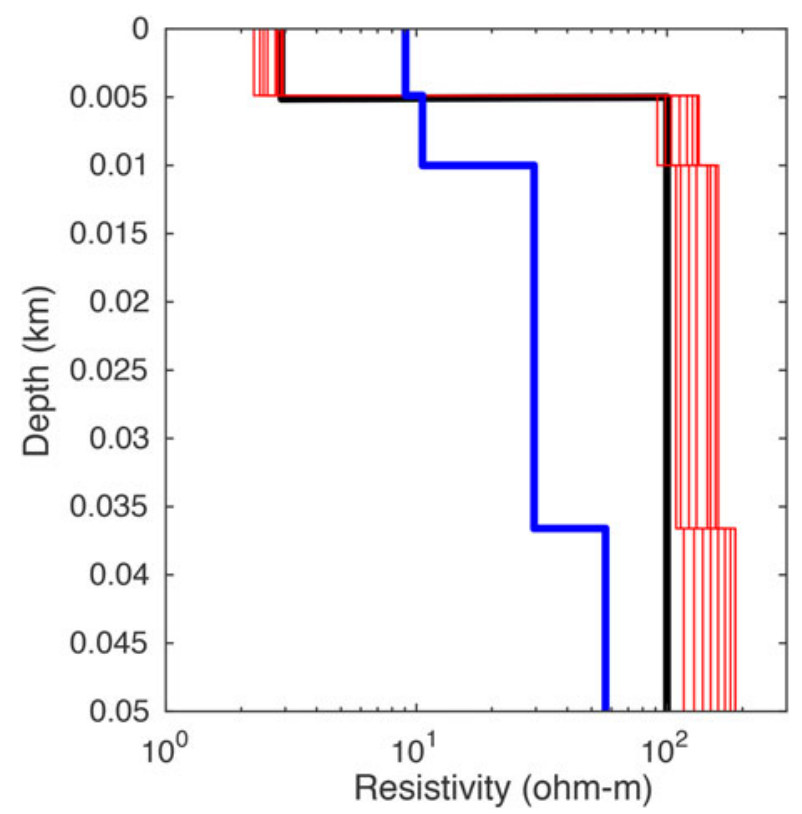

Fig. 10. Vertical resistivity profiles from the smooth $M T$ inversion (blue line) and the lake-depth-constrained MT inversion (red lines) sampled every $200 \mathrm{~m}$ laterally across the hypothetical lake. Black line shows the true model.

anomalies is smaller than that of the corresponding MT anomalies, suggesting that FDEM data are perhaps less ideal for subglacial mapping. However, we note that there may be practical advantages to collecting FDEM data: very large dipole moments could be generated using a strong source transmitter, so that the signal-to-noise ratio greatly exceeds that of MT data. In this case, the anomalies may in practice be relatively larger than the MT anomalies when measured relative to the data noise level.

\subsection{Grounding zone study}

In this section, we conduct a model study to highlight how EM data can constrain hydrologic structure near the
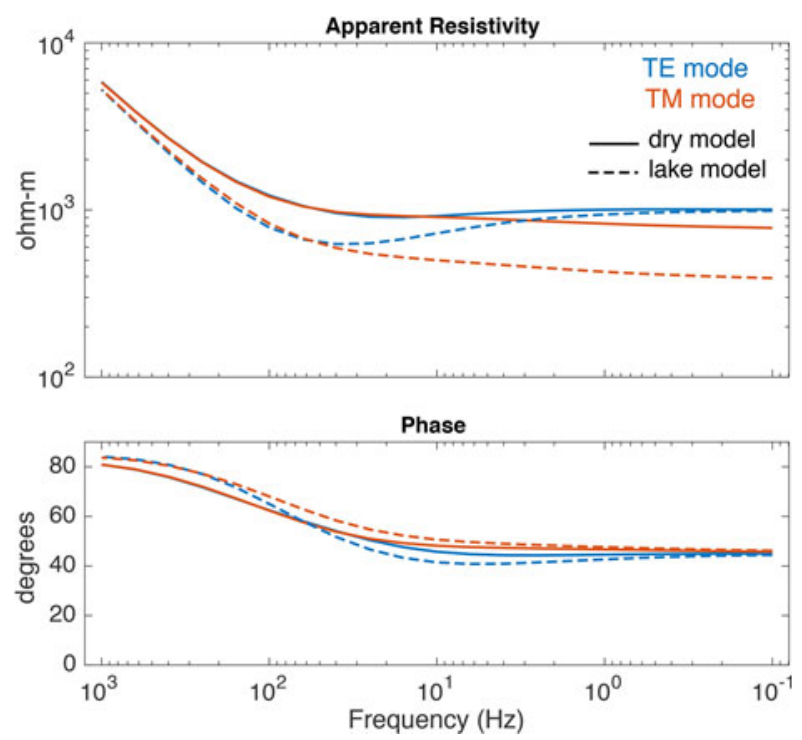

Fig. 11. Transverse electric (TE) and magnetic (TM) apparent resistivity and phase MT responses for a receiver located at the center of the lake in our SLW-like domain (lake model) and in a similar model with the lake removed (dry model).
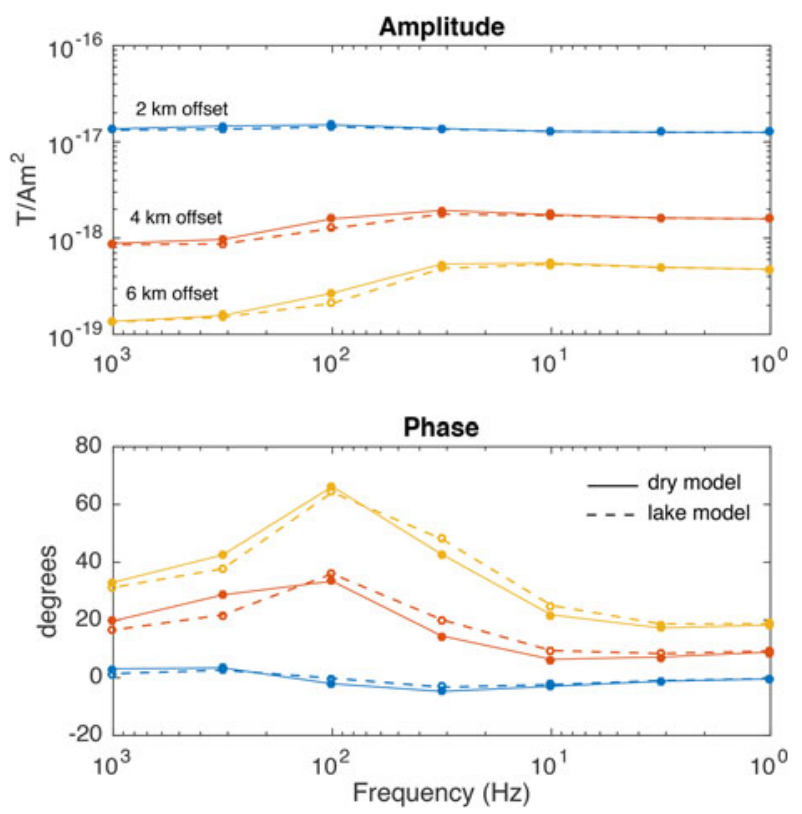

Fig. 12. Amplitude and phase FDEM responses for data at 2, 4 and 6 $\mathrm{km}$ offset centered over the lake for our SLW-like domain (lake model) and in a similar model with the lake removed (dry model).

grounding line of an ice stream. We are motivated by recent observations of a subglacial estuary at the grounding zone of Whillans Ice Stream, where a combination of radio-echo sounding, kinematic GPS, and active-source seismic data were used to infer the existence of an estuarylike feature (Horgan and others, 2013); here, we show how EM data could be used to image such an estuary via the high conductivity of saline estuary water. Figure 13 shows the hypothetical model of grounding zone electrical resistivity. Our model, modified from an inversion of a groundbased gravity survey (Muto and others, 2013), consists of $\sim 700 \mathrm{~m}$ of ice underlain by $\sim 1 \mathrm{~km}$ of moderately porous sediments. Seaward of the grounding line, the model contains seawater-saturated marine sediments beneath a thin ocean cavity that is only a few meters thick. Landward of the grounding line, the shallow sediments are significantly more resistive, which could reflect either significantly fresher pore-water due to inflow from the upstream hydrologic system or from overall lower porosity. We include a seawater intrusion zone landward of the grounding line to represent an estuary with $1 \mathrm{~m}$ thickness and $5 \mathrm{~km}$ lateral extent. This feature could be transient, arising from a tidally driven pulse of seawater that moves inward from the grounding line (Horgan and others, 2013; Walker and others, 2013). To demonstrate sensitivity to deeper components of the system, we added two relatively conductive $2 \Omega$-m prisms, labeled A and B, which represent high porosity ( 20\%) sandstones filled with conductive seawater. Since our previous model study shows similar results for both MT and FDEM data, here we only consider MT data. MT responses were generated at 36 frequencies spanning from 0.001 to 1000 $\mathrm{Hz}$ for 31 receivers spaced every $500 \mathrm{~m}$ along the ice surface.

Pseudosections of the MT response anomaly show the relative differences between the responses from models with and without the seawater intrusion are up to $25 \%$ (Fig. 14). Both TE- and TM-mode responses have anomalies that are primarily confined to receivers located over the 


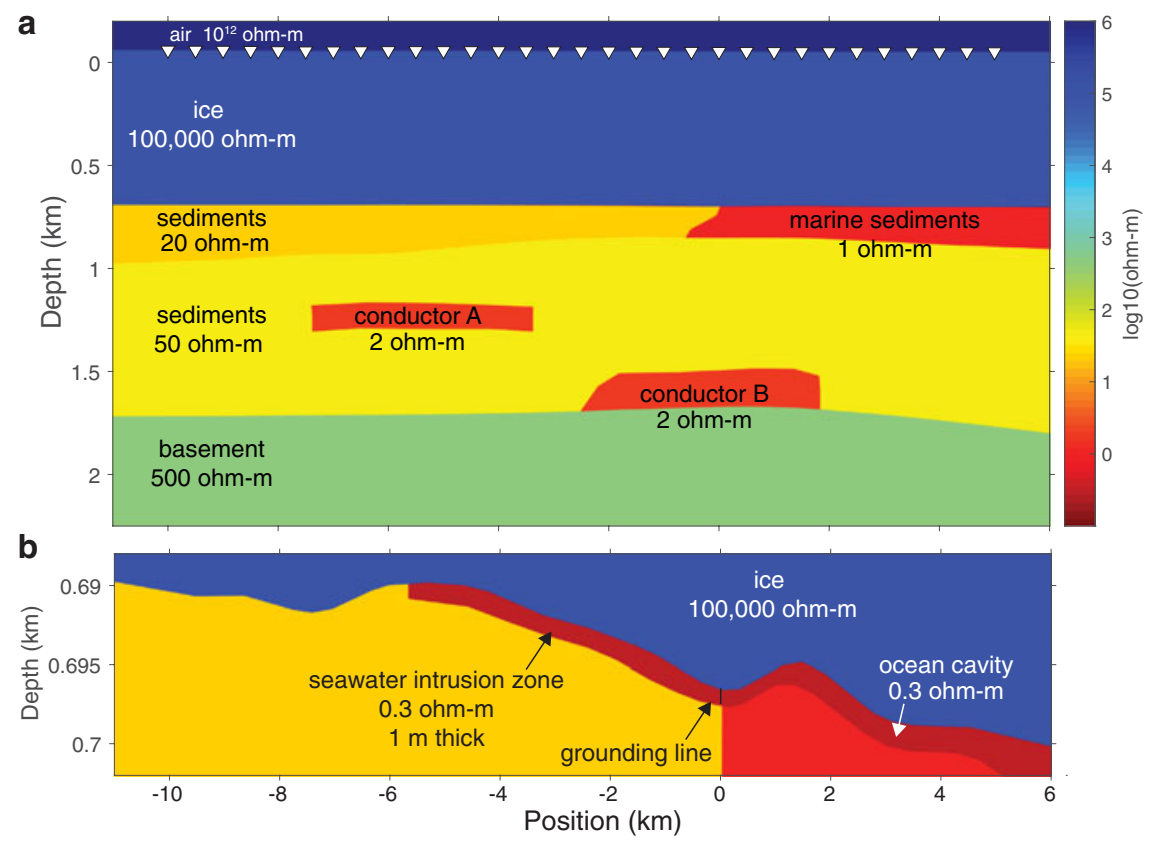

Fig. 13. (a) Grounding zone model study. The model includes $\sim 700 \mathrm{~m}$ of ice overlying $1 \mathrm{~km}$ of moderately porous sediments above a resistive basement. The grounding line is located at $0 \mathrm{~km}$ position. A conductive $\sim 200 \mathrm{~m}$ thick layer of seawater-saturated marine sediments is underneath the floating portion of the ice. Two conductive prisms labeled A and B are located within the deeper sediments. White triangles show the MT receiver locations on the ice surface. (b) Close up of the ice base showing a 1-3 m thick ocean cavity to the right (downstream) of the grounding line and a $5 \mathrm{~km}$ wide by $1 \mathrm{~m}$ thick transient seawater intrusion zone to the left (upstream) of the grounding line.

seawater intrusion. The responses also exhibit TE- and TMmode effects that are similar to those seen in our earlier subglacial lake study; for both TE and TM modes, there is a centrally located anomaly $\sim 10-100 \mathrm{~Hz}$, but at lower frequencies, the TM mode also has a frequency-independent anomaly consistent with a galvanic distortion of the EM field. The $25 \%$ peak anomaly magnitude from this $2 \mathrm{D}$ conductive structure is significantly smaller than the $>100 \%$ anomaly predicted by the 1D sensitivity study in Figure 4, illustrating that the limited lateral extent of this feature reduces its overall impact on the MT response compared with a 1D layer. Even with a smaller magnitude anomaly, this experiment suggests that a continuously recording MT receiver deployed upstream of the grounding line could effectively identify transient seawater intrusions and help quantify potentially significant grounding zone processes.

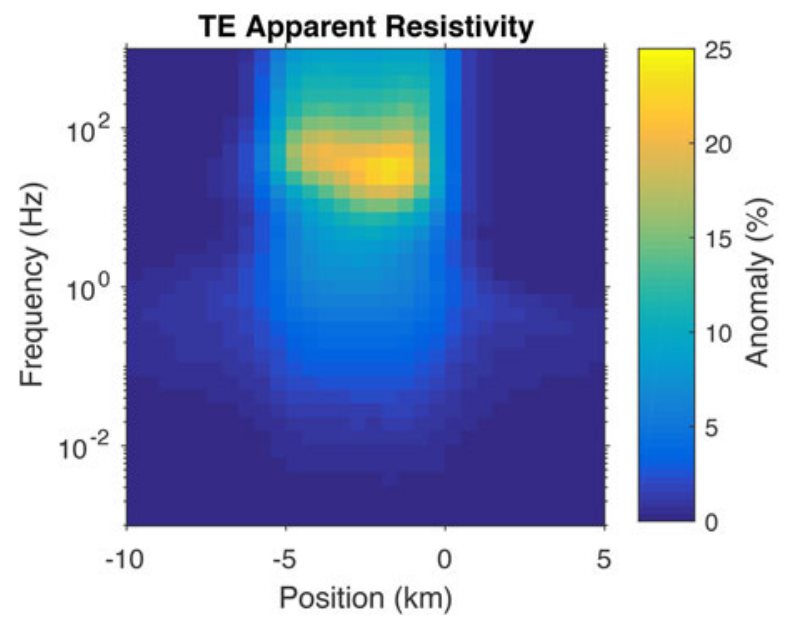

Figure 15 shows the result of inverting synthetic data that included $1 \%$ random Gaussian noise. The inversion was started from a uniform $100 \Omega$-m starting model, and the ice layer and ocean cavity were held as fixed structures with known resistivities. The inversion's smoothness constraint was relaxed along the base of the seawater intrusion zone, allowing for a sharp jump in resistivity, as was done previously in the subglacial lake study in Figure $9 \mathrm{~d}$. The broader view (Fig. 15a) shows that MT data can image all of the large-scale components of the original model: conductors $A$ and $B$, the resistivity difference between the marine sediments and the sediments beneath the grounded ice, and the higher resistivity of the deeper low porosity basement. Details from the inversion near ice-bed interface (Fig. 15b) shows that the inversion recovered well the low resistivity in the seawater intrusion channel along its entire length.

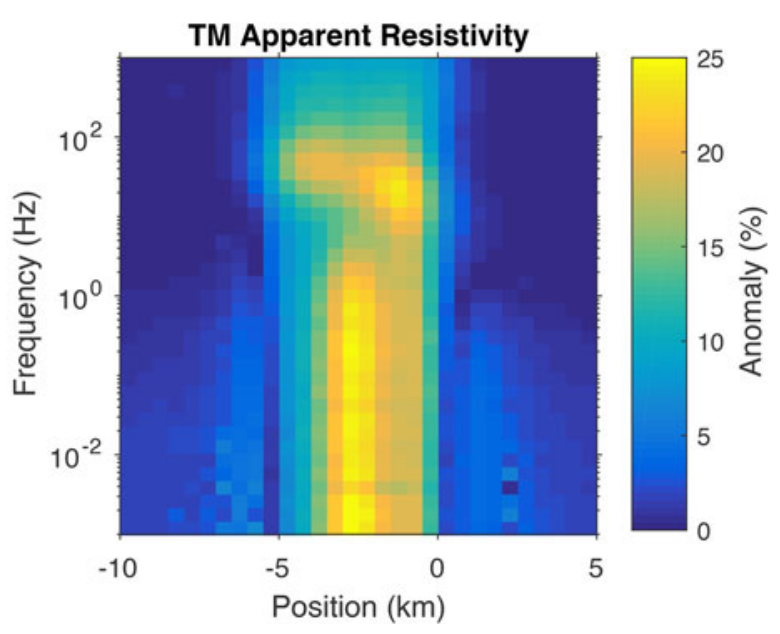

Fig. 14. Relative anomaly in the MT responses due to the $1 \mathrm{~m}$ thick seawater intrusion at -5 to $0 \mathrm{~km}$ lateral position. The anomaly is calculated by taking the relative difference in the response from models with and without the seawater intrusion and is shown as a function of frequency and receiver position. 
a

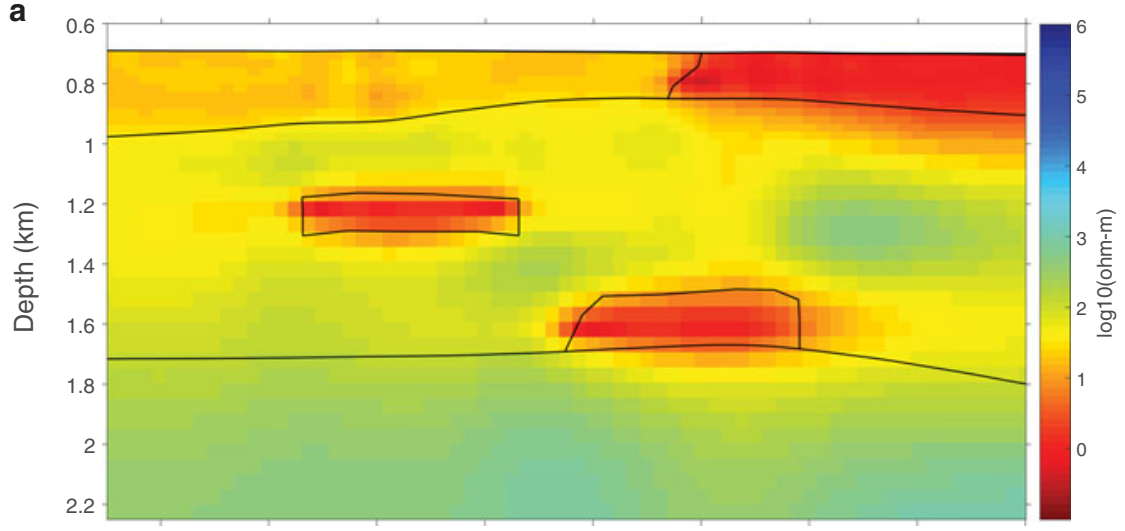

b

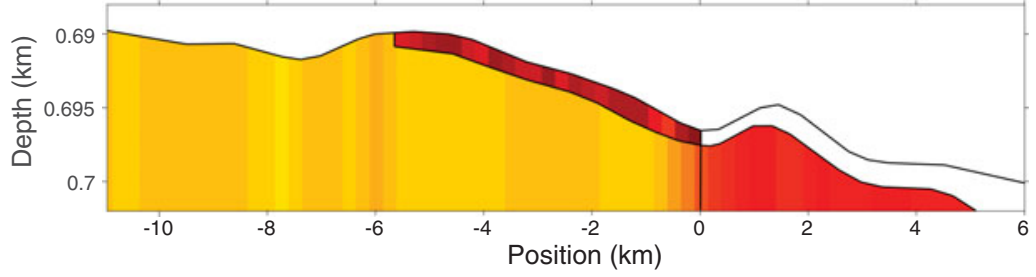

Fig. 15. Electrical resistivity obtained by non-linear inversion of synthetic MT data generated for the grounding zone model. Panel (a) shows the deeper subglacial region, while (b) shows the detail recovered near the subglacial seawater intrusion zone at -5 to $0 \mathrm{~km}$ position. The inversion's smoothness constraint was relaxed along the base of the seawater intrusion zone to allow for a sharp jump in resistivity. The ice layer and ocean cavity were held as fixed structures with known resistivities. Black lines show the structural boundaries from the true model shown in Figure 13.

Despite the effective overall performance of this inversion for recovering model structure, it is worthwhile to consider some limitations of EM data. Comparison with the sharp boundaries of the original forward model shows a significant degree of lateral and vertical smoothing in the inverted resistivity that reflects the spatial resolution limits of diffusive EM data. The degree of smoothness in the inverted model can be used to infer limitations in the depth and lateral resolution of EM data. The grounding zone forward model contains sufficient space between the conductors, so they can be uniquely resolved in an inversion; however, if the conductors are too close together (vertically or laterally), the inversion would likely smooth them together into a single conjoined feature. Likewise, the forward model contains conductivity contrast between the conductors and the sediments that are at least an order of magnitude; smaller conductivity contrasts would be more difficult to image. However, despite the smoothed feature boundaries and resolution limitations, this experiment shows that MT data can be used to discern zones of high porosity from low porosity and between saline and fresh water components, and thus could be used for large-scale characterization of the hydrological regime at a grounding zone. Similar to the subglacial lake experiment, some of these limitations could be mitigated with additional knowledge of geologic structure from active-source seismic data.

\section{DISCUSSION}

Our modeling studies show that ground-based EM data can detect and map subglacial groundwater over a range of conditions. Based on these studies, the minimum thickness of lake water that is detectable beneath $\sim 1 \mathrm{~km}$ of ice is about a few meters, but this depends on the water conductivity, with more conductive water being easier to detect. At a grounding zone where the ice is thinner, EM data could more easily detect and map a subglacial estuary since the water conductivity could be expected to be close to the high value of seawater; here, EM could also be used to characterize seawater mixing with groundwater upstream of the grounding line. Our studies also show that EM data can constrain the bulk conductivity of the deeper groundwater system contained in till, sediments and fractured bedrock.

The $2 \mathrm{D}$ inversion simulations showed that the passive MT method and the controlled-source FDEM method are able to resolve the subglacial lake and deeper structure with similar resolution when the ice is $\sim 1 \mathrm{~km}$ thick. Thus, we can not recommend one method over the other based on theoretical considerations alone, and practical considerations, such as survey efficiency and reliability, will be paramount in deciding which method will serve a particular survey best. When the ice is much thicker than $\sim 2 \mathrm{~km}$, the anomalous FDEM signals become too small to be easily detectable; thus, for surveys in areas with thicker ice, such as central West Antarctica or most of East Antarctica, we recommend collecting MT data rather than FDEM data.

Reliable MT responses in the subglacial sensitive band of $0.1-1000 \mathrm{~Hz}$ can be obtained with as little as a few hours of recording time, and so in ideal conditions, up to a few stations could be collected per day for a single team working in the field. Due to the high resistivity of firn, the contact resistance of the electric bipoles used to measure the telluric fields can be as high as $1 \mathrm{M} \Omega$ leading to enhanced capacitive coupling with the ground, and so specialized ultra-high-input impedance buffer amplifiers and electrodes must be used to minimize these effects (Zonge and Hughes, 1985). Wannamaker and others (2004) and Peacock and Selway (2016) have demonstrated the effectiveness of this approach for measuring electric fields in Antarctica.

An advantage of the FDEM approach is that the receiver only needs to measure the vertical magnetic field induced by the transmitter, and so there is no need for special electric 
bipoles and their time-consuming installation. Conversely, the induction coil magnetometers used for FDEM recordings are highly sensitive to vibrations, and so some care may need to be taken in stabilizing them by burial or other wind shielding techniques, so that low-noise measurements can be obtained. We expect that the FDEM measurements could potentially be obtained as quickly as a few minutes per station for a given transmitter location. Thus, perhaps dozens of stations could be obtained per day by a single team.

For the FDEM transmitter antenna, the dipole moment generated is a function of loop size and current required (moment scales as $L^{2} I$, where $L$ is the loop side length and I is the current), both of which present their own logistical considerations: size is a trade-off between time and space required to lay out the loop, while the current in the loop depends on, via Ohm's Law, the output voltage of the transmitter and the resistance of the loop wire. A dipole moment of $10^{6} \mathrm{Am}^{2}$, for example, can be generated with a $6.25 \mathrm{~A}$ current through a $400 \times 400 \mathrm{~m}^{2}$ loop. Assuming a $1.63 \mathrm{~mm}$ diameter (14 AWG) copper antenna wire, the $1.6 \mathrm{~km}$ wire length has a resistance of $\sim 13.3 \Omega$, so the transmitter would only need an output voltage of $\sim 83 \mathrm{~V}$ to generate enough current for this dipole moment. Smaller loops with larger currents could also be designed to generate the same dipole moment, but care should be taken to ensure the antenna wire is of sufficient diameter to safely carry the expected current load.

Finally, the sensitivity of MT data at frequencies above $1000 \mathrm{~Hz}$ to the ice resistivity suggests that such high-frequency EM data might be useful for mapping the internal structure of an ice sheet since its resistivity depends on temperature, density and impurity content (Kulessa, 2007). Further study is needed to determine the range of ice conditions that would be detectable with EM data as well as to examine how displacement currents and more complicated conduction mechanisms would impact such high-frequency measurements.

\section{SUMMARY}

We perform a suite of synthetic modeling studies to test the feasibility of EM methods for mapping near-surface subglacial conductivity structure. We demonstrate that both MT and FDEM methods are viable paths forward for enhancing our ability to image the wet subglacial environment. We show that EM methods can identify thin, fresh subglacial lakes and grounding zone saline estuaries as conductivity anomalies well outside the expected noise floor of the data and that EM data can retrieve bulk conductivity estimates for sediment packages of varying thickness. A potential limitation of EM imaging of subglacial groundwater is that the water resistivity depends highly on its dissolved ion content, so that nearly pure fresh water can be difficult to distinguish from bedrock. Despite this apparent limitation, available groundwater conductivity measurements from the edges of the Antarctic ice sheet show high conductivities consistent with brackish to saline ion concentrations, and therefore these regions are highly suitable for EM imaging. Although the resolution of EM data is limited by diffusion physics, so that conductivity boundaries are often imaged as smoothed features, our study shows that they can be effectively combined with higher resolution stratigraphic depth constraints from seismic and radar data to create an improved image of subglacial conditions. While our 1D and 2D studies may be somewhat simplistic compared with potentially more complex target geometries that may be encountered in the field, they provide some first-order insights that can be used as a starting point for planning the logistical constraints of future surveys. The conductivity structure of the subglacial system, including the hydrology of the ice-bed interface and deeper groundwater, is difficult to observe; we suggest the application of passive and active EM methods can reveal new insights into this enigmatic environment, providing important constraints for the regional glaciological, geological, biological and oceanographic systems, all of which are impacted by subglacial conductive fluids.

\section{ACKNOWLEDGEMENTS}

We thank Martyn Unsworth and Martin Siegert for useful review comments that helped shape this paper.

\section{REFERENCES}

Alley KE, Scambos TA, Siegfried MR and Fricker HA (2016) Impacts of warm water on basal channel formation and links to Antarctic ice shelf stability. Nat. Geosci., 9(4), 290-293 (doi: 10.1038/ngeo2675)

Alley RB, Anandakrishnan S, Bentley CR and Lord N (1994) A waterpiracy hypothesis for the stagnation of Ice Stream C, Antarctica. Ann. Glaciol., 20(1), 187-194

Anandakrishnan S and Alley RB (1997) Stagnation of ice stream C, West Antarctica by water piracy. Geophys. Res. Lett., 24(3), 265-268

Archie G (1942) The electrical resistivity log as an aid in determining some reservoir characteristics. Trans. Am. Inst. Min. Metall. Eng., 146, 54-61

Baba K, Chave AD, Evans RL, Hirth G and Mackie RL (2006) Mantle dynamics beneath the East Pacific Rise at $17^{\circ} \mathrm{S}$ : insights from the Mantle Electromagnetic and Tomography (MELT) experiment. J. Geophys. Res., 111(B2), (doi: 10.1029/2004jb003598)

Beblo $M$ and Liebig V (1990) Magnetotelluric measurements in Antarctica. Phys. Earth Planet. Inter., 60(1-4), 89-99 (doi: 10.1016/ 0031-9201(90)90251-r)

Bell RE (2008) The role of subglacial water in ice-sheet mass balance. Nat. Geosci., 1(5), 297-304

Bentley CR (1977) Electrical resistivity measurements on the Ross Ice Shelf. J. Glaciol., 18(78)

Bentley CR, Jezek KC, Blankenship DD, Lovell JS and Albert DG (1979) Geophysical investigation of the Dome $C$ area, Antarctica. Antarct. J. USA, 14(5), 98-100

Blankenship DD, Bentley CR, Rooney ST and Alley RB (1986) Seismic measurements reveal a saturated porous layer beneath an active Antarctic ice stream. Nature, 322(6074), 54-57 (doi: 10.1038/322054a0)

Blankenship DD, Bentley C, Rooney S and Alley RB (1987) Till beneath ice stream b: 1. properties derived from seismic travel times.J. Geophys. Res. Solid Earth (1978-2012), 92(B9), 8903-8911

Brace WF and Orange AS (1968) Further studies of effects of pressure on electrical resistivity of rocks. J. Geophys. Res. Solid Earth, 73 (16), 5407-5420

Carter SP and Fricker HA (2012) The supply of subglacial meltwater to the grounding line of the Siple Coast, West Antarctica. Ann. Glaciol., 53(60), 267-280 (doi: 10.3189/2012aog60a119)

Carter SP, Fricker HA and Siegfried MR (2017) Antarctic subglacial lakes drain through sediment-floored canals: theory and model testing on real and idealized domains. Cryosphere, 11, 381405 (doi: 10.5194/tc-11-381-2017) 
Chave AD and Cox CS (1982) Controlled electromagnetic sources for measuring electrical-conductivity beneath the oceans. 1. Forward problem and model study. J. Geophys. Res. Solid Earth, 87, 5327-5338

Chave AD and Jones AG (2012) The magnetotelluric method: theory and practice. Cambridge University Press, Cambridge

Christiansen AV, Auken E and Sørensen K (2006) The transient electromagnetic method. In Groundwater geophysics. Springer Science Business Media, Springer-Verlag, Berlin, Heidelberg, 179-225

Christianson K, Jacobel RW, Horgan HJ, Anandakrishnan S and Alley RB (2012) Subglacial Lake Whillans — Ice-penetrating radar and GPS observations of a shallow active reservoir beneath a West Antarctic ice stream. Earth Planet. Sci. Lett., 331-332, 237-245 (doi: 10.1016/j.epsl.2012.03.013)

Christner BC and 11 others (2014) A microbial ecosystem beneath the West Antarctic ice sheet. Nature, 512(7514), 1-9 (doi: 10.1038/nature13667)

Christoffersen P and Tulaczyk S (2003) Response of subglacial sediments to basal freeze-on 1 . Theory and comparison to observations from beneath the West Antarctic Ice Sheet. J. Geophys. Res. Solid Earth, 108(B4)

Christoffersen $\mathrm{P}$, Bougamont $\mathrm{M}$, Carter SP, Fricker HA and Tulaczyk S (2014) Significant groundwater contribution to Antarctic ice streams hydrologic budget. Geophys. Res. Lett., 41(6), 2003-2010 (doi: 10.1002/2014gl059250)

Danielsen JE, Auken E, Jørgensen F, Søndergaard V and Sørensen KI (2003) The application of the transient electromagnetic method in hydrogeophysical surveys. J. Appl. Geophys., 53(4), 181198 (doi: 10.1016/j.jappgeo.2003.08.004)

Dowdeswell JA and Evans S (2004) Investigations of the form and flow of ice sheets and glaciers using radio-echo sounding. Rep. Prog. Phys., 67(10), 1821

Dowdeswell JA and Siegert MJ (1999) The dimensions and topographic setting of Antarctic subglacial lakes and implications for large-scale water storage beneath continental ice sheets. Geol. Soc. Am. Bull., 111(2), 254-263

Dugan HA and 7 others (2015) Subsurface imaging reveals a confined aquifer beneath an ice-sealed Antarctic lake. Geophys. Res. Lett., 42(1), 96-103 (doi: 10.1002/2014gl062431)

Elsworth CW and Suckale J (2016) Subglacial drainage may induce rapid ice flow rearrangement in West Antarctica. Geophys. Res. Lett. (doi: 10.1002/2016GL070430)

Engelhardt H and Kamb B (1997) Basal hydraulic system of a West Antarctic ice stream: constraints from borehole observations. J. Glaciol., 43(144), 207-230

Foley $\mathrm{N}$ and 7 others (2015) Helicopter-borne transient electromagnetics in high-latitude environments: an application in the McMurdo Dry Valleys, Antarctica. Geophysics, 81(1), WA87WA99 (doi: 10.1190/geo2015-0186.1)

Fricker HA and Scambos T (2009) Connected subglacial lake activity on lower Mercer and Whillans Ice Streams, West Antarctica, 2003-2008. J. Glaciol., 55(190), 303-315

Fricker HA, Scambos T, Bindschadler R and Padman L (2007) An active subglacial water system in West Antarctica mapped from space. Science, 315(5818), 1544

Garcia X and Jones AG (2010) Internal structure of the western flank of the Cumbre Vieja volcano, La Palma, Canary Islands, from land magnetotelluric imaging. J. Geophys. Res., 115(B7) (doi: 10.1029/2009jb006445)

Gladish CV, Holland DM, Holland PR and Price SF (2012) Ice-shelf basal channels in a coupled ice/ocean model. J. Glaciol., $\mathbf{5 8}$ (212), 1227-1244 (doi: 10.3189/2012jog12j003)

Goodwin ID (1988) The nature and origin of a jökulhlaup near Casey Station, Antarctica. J. Glaciol. (doi: 10.3198/1988JoG34116-95-101)

Gorman MR and Siegert MJ (1999) Penetration of Antarctic subglacial lakes by VHF electromagnetic pulses: information on the depth and electrical conductivity of basal water bodies. J. Geophys. Res., 104 (B12), 29311-29320 (doi: 10.1029/1999JB900271)

Gray L and 5 others (2005) Evidence for subglacial water transport in the West Antarctic Ice Sheet through three-dimensional satellite radar interferometry. Geophys. Res. Lett., 32(3), L03501, ISSN 0094-8276

Hessler VP and Jacobs J (1966) A telluric current experiment on the Antarctic ice cap. Nature, 210, 190-191 (doi: 10.1038/210190a0)

Hochstein M (1967) Electrical resistivity measurements on ice sheets. J. Glaciol., 6(47), 623-633

Horgan HJ and 7 others (2012) Subglacial Lake Whillans - Seismic observations of a shallow active reservoir beneath a West Antarctic ice stream. Earth Planet. Sci. Lett., 331, 201-209

Horgan HJ and 7 others (2013) Estuaries beneath ice sheets. Geology, 41(11), 1159-1162 (doi: 10.1130/G34654.1)

Hubbard A, Lawson W and Anderson B (2004) Evidence for subglacial ponding across Taylor Glacier, Dry Valleys, Antarctica. Ann. Glaciol., 39(1), 79-84 (doi: 10.3189/172756404781813970)

Jenkins A (2011) Convection-driven melting near the grounding lines of ice shelves and tidewater glaciers. J. Phys. Oceanogr., 41(12), 2279-2294 (doi: 10.1175/jpo-d-11-03.1)

Joughin I, Shean DE, Smith BE and Dutrieux P (2016) Grounding line variability and subglacial lake drainage on Pine Island Glacier, Antarctica. Geophys. Res. Lett. (doi: 10.1002/2016GL070259)

Kamb B (1987) Glacier surge mechanism based on linked cavity configuration of the basal water conduit system. J. Geophys. Res., 92(B9), 9083-9100 (doi: 10.1029/JB092iB09p09083)

Kapitsa AP, Ridley JK, Robin GQ, Siegert MJ and Zotikov IA (1996) A large deep freshwater lake beneath the ice of central East Antarctica. Nature, 381, 684-686

Kennicutt MC and 74 others (2014) A roadmap for Antarctic and Southern Ocean science for the next two decades and beyond. Antarct. Sci., 27(01), 3-18 (doi: 10.1017/ S0954102014000674)

Key K (2012) Is the fast Hankel transform faster than quadrature? Geophysics, 77(3), F21-F30 (doi: 10.1190/geo2011-0237.1)

Key K (2016) MARE2DEM: a 2-D inversion code for controlledsource electromagnetic and magnetotelluric data. Geophys. J. Int., 207(1), 571-588 (doi: 10.1093/gji/ggw290)

Key K and Ovall J (2011) A parallel goal-oriented adaptive finite element method for 2.5-D electromagnetic modelling. Geophys. J. Int., 186(1), 137-154 (doi: 10.1111/j.1365-246x.2011.05025.x)

Key K, Constable S, Liu L and Pommier A (2013) Electrical image of passive mantle upwelling beneath the northern East Pacific Rise. Nature, 495(7442), 499-502 (doi: 10.1038/nature11932)

Kirsch R (2006) Groundwater geophysics: a tool for hydrogeology. Springer-Verlag, Berlin, Heidelberg

Kulessa B (2007) A critical review of the low-frequency electrical properties of ice sheets and glaciers. J. Environ. Eng. Geophys., 12(1), 23-36

Le Brocq AM and 10 others (2013) Evidence from ice shelves for channelized meltwater flow beneath the Antarctic Ice Sheet. Nat. Geosci., 6(11), 945-948 (doi: 10.1038/ngeo1977)

Lliboutry L (1964) Sub-glacial 'Supercavitation' as a cause of the rapid advances of glaciers. Nature, 202(4927), 77

Marsh OJ and 6 others (2016) High basal melting forming a channel at the grounding line of Ross Ice Shelf, Antarctica. Geophys. Res. Lett., 43(1), 250-255 (doi: 10.1002/2015gl066612)

Meqbel NMM, Ritter O and Group D (2013) A magnetotelluric transect across the Dead Sea Basin: electrical properties of geological and hydrological units of the upper crust. Geophys. J. Int., 193(3), 1415-1431 (doi: 10.1093/gji/ggt051)

Michaud AB and 7 others (2016) Solute sources and geochemical processes in Subglacial Lake Whillans, West Antarctica. Geology, 44(5), 347-350 (doi: 10.1130/G37639.1)

Mikucki JA and 8 others (2015) Deep groundwater and potential subsurface habitats beneath an Antarctic dry valley. Nat. Commun., 6, 6831 (doi: 10.1038/ncomms7831) 
Millgate T, Holland PR, Jenkins A and Johnson HL (2013) The effect of basal channels on oceanic ice-shelf melting. J. Geophys. Res. Oceans, 118(12), 6951-6964 (doi: 10.1002/2013jc009402)

Muto A, Christianson K, Horgan HJ, Anandakrishnan S and Alley RB (2013) Bathymetry and geological structures beneath the Ross Ice Shelf at the mouth of Whillans Ice Stream, West Antarctica, modeled from ground-based gravity measurements. J. Geophys. Res. Solid Earth, 118(8), 4535-4546

Nabighian MN (ed.) (1987) Electromagnetic methods in applied geophysics - theory, Volume 1. Society of Exploration Geophysicists, Tulsa

Naif S, Key K, Constable S and Evans RL (2013) Melt-rich channel observed at the lithosphere-asthenosphere boundary. Nature, 495(7441), 356-359 (doi: 10.1038/nature11939)

Nenna V, Herckenrath D, Knight R, Odlum N and McPhee D (2013) Application and evaluation of electromagnetic methods for imaging saltwater intrusion in coastal aquifers: seaside Groundwater Basin, California. Geophysics, 78(2), B77-B88 (doi: 10.1190/geo2012-0004.1)

Nichols EA, Morrison HF and Clarke J (1988) Signals and noise in measurements of low-frequency geomagnetic fields. J. Geophys. Res. Solid Earth, 93(11), 13794-13754

Parizek R, Alley RB and Hulbe CL (2003) Subglacial thermal balance permits ongoing grounding-line retreat along the Siple Coast of West Antarctica. Ann. Glaciol., 36(1), 251-256

Peacock JR and Selway K (2016) Magnetotelluric investigation of the Vestfold Hills and Rauer Group, East Antarctica. J. Geophys. Res. Solid Earth (doi: 10.1002/(ISSN)2169-9356)

Perkin R and Lewis E (1980) The practical salinity scale 1978: fitting the data. IEEE J. Ocean. Eng., 5(1), 9-16 (doi: 10.1109/joe.1980. 1145441)

Petrenko VF and Whitworth RW (2002) Physics of ice. Oxford University Press, Oxford (doi: 10.1093/acprof:oso/9780198518 945.001.0001)

Pirjola RJ (1998) Modelling the electric and magnetic fields at the Earth's surface due to an auroral electrojet. J. Atmos. Sol.-Terr. Phys., 60(11), 1139-1148 (doi: 10.1016/s1364-6826(98)00070-4)

Reynolds JM and Paren JG (1984) Electrical resistivity of ice from the Antarctic Peninsula, Antarctica. J. Glaciol., 30(106), 289-295

Rignot E and Steffen K (2008) Channelized bottom melting and stability of floating ice shelves. Geophys. Res. Lett., 35(2) (doi: 10.1029/2007gl031765)

Robin GdQ (1955) Ice movement and temperature distribution in glaciers and ice sheets. J. Glaciol., 2(18), 523-532

Röthlisberger $\mathrm{H}$ (1972) Water pressure in intra- and subglacial channels. J. Glaciol., 11, 177-203

Ruotoistenmäki T and Lehtimäki J (1997) Estimation of permafrost thickness using ground geophysical measurements, and its usage for defining vertical temperature variations in continental ice and underlying bedrock. J. Glaciol., 43(1), 359-364

Scambos TA, Berthier E and Shuman CA (2011) The triggering of subglacial lake drainage during rapid glacier drawdown: crane Glacier, Antarctic Peninsula. Ann. Glaciol., 52(59), 74-82

Schroeder DM, Blankenship DD, Raney RK and Grima C (2015) Estimating subglacial water geometry using radar bed echo specularity: application to Thwaites Glacier, West Antarctica. IEEE Geosci. Remote Sens. Lett., 12(3), 443-447

Sergienko OV (2013) Basal channels on ice shelves. J. Geophys. Res. Earth Surf., 118(3), 1342-1355 (doi: 10.1002/jgrf.20105)

Shabtaie $S$ and Bentley CR (1994) Electrical resistivity measurements on ice stream. B, Antarctica. Ann. Glaciol., 20(1), 129-136 (doi: 10.3189/172756494794587465)

Shabtaie S, Bentley CR, Blankenship DD, Lovell JS and Gassett RM (1980) Dome c geophysical survey, 1979-80. Antarct. J. USA, 15 (5), 2-5

Siegert MJ and Bamber JL (2000) Subglacial water at the heads of Antarctic ice-stream tributaries. J. Glaciol., 46, 702-703

Siegert MJ, Carter S, Tabacco I, Popov S and Blankenship DD (2005) A revised inventory of Antarctic subglacial lakes. Antarct. Sci., 17 (03), 453-460
Siegert MJ, Popov S and Studinger M (2011) Subglacial Lake Vostok: a review of geophysical data regarding its physiographical setting. In Siegert M, Kennicutt C and Bindschadler B, eds. Subglacial antarctic aquatic environments. AGU Geophysical Monograph 192, Washington, DC, 45-60

Siegert MJ and 8 others (2014) Boundary conditions of an active West Antarctic subglacial lake: implications for storage of water beneath the ice sheet. Cryosphere, 8(1), 15-24 (doi: 10.5194/tc-8-15-2014)

Siegert MJ and 7 others (2017) Antarctic subglacial groundwater: a concept paper on its measurement and potential influence on ice flow. In Siegert MJ, Jamieson S and White D, eds. Exploration of subsurface Antarctica uncovering past changes and modern processes, Geological Society, London (doi: 10.17863/CAM.8570)

Siegfried MR, Fricker HA, Roberts M, Scambos TA and Tulaczyk S (2014) A decade of West Antarctic subglacial lake interactions from combined ICESat and CryoSat-2 altimetry. Geophys. Res. Lett., 41(3), 891-898 (doi: 10.1002/2013GL058616)

Siegfried MR, Fricker HA, Carter SP and Tulaczyk S (2016) Episodic ice velocity fluctuations triggered by a subglacial flood in West Antarctica. Geophys. Res. Lett., 43(6), 2640-2648 (doi: 10.1002/2016GL067758)

Smith AM (1997) Basal conditions on Rutford ice stream, West Antarctica, from seismic observations. J. Geophys. Res. Solid Earth, 102(B1), 543-552

Smith BE, Fricker HA, Joughin IR and Tulaczyk S (2009) An inventory of active subglacial lakes in Antarctica detected by ICESat (2003-2008). J. Glaciol., 55(192), 573-595, ISSN 0022-1430

Smith BE, Gourmelen N, Huth A and Joughin I (2016) Connected subglacial lake drainage beneath Thwaites Glacier, West Antarctica. Cryosphere Discuss. (doi: 10.5194/tc-2016-180)

Spigel RH and Priscu JC (1996) Evolution of temperature and salt structure of Lake Bonney, a chemically stratified Antarctic lake. Hydrobiologia, 321, 177-190

Stearns LA, Smith BE and Hamilton GS (2008) Increased flow speed on a large East Antarctic outlet glacier caused by subglacial floods. Nat. Geosci., 1(12), 827-831

Tabacco I, Cianfarra P, Forieri A, Salvini F and Zirizotti A (2006) Physiography and tectonic setting of the subglacial lake district between Vostok and Belgica subglacial highlands (Antarctica). Geophys. J. Int., 165(3), 1029-1040

Tulaczyk S and 15 others and the WISSARD Science Team (2014) WISSARD at Subglacial Lake Whillans, West Antarctica: scientific operations and initial observations. Ann. Glaciol., 55(65), 51-58 (doi: 10.3189/2014AoG65A009)

Unsworth M, Egbert G and Booker J (1999) High-resolution electromagnetic imaging of the San Andreas Fault in central California. J. Geophys. Res., 104(B1), 1131-1150 (doi: 10.1029/98jb01755)

Vaughan DG, Corr HF, Smith AM, Pritchard HD and Shepherd A (2008) Flow-switching and water piracy between Rutford Ice Stream and Carlson Inlet, West Antarctica. J. Glaciol., 54(184), $41-48$

Vaughan DG and 8 others (2012) Subglacial melt channels and fracture in the floating part of Pine Island Glacier, Antarctica. J. Geophys. Res., 117(F3) (doi: 10.1029/2012jf002360)

Vick-Majors TJ (2016) Biogeochemical processes in Antarctic aquatic environments: linkages and limitations. (PhD thesis, Montana State University, Bozeman, MT)

Wadham JL and 12 others (2012) Potential methane reservoirs beneath Antarctica. Nature, 488(7413), 633-637 (doi: 10.1038/ nature11374

Wadham JL and 6 others (2013) The potential role of the Antarctic Ice Sheet in global biogeochemical cycles. Earth Environ. Sci. Trans. R. Soc. Edinb., 104(01), 55-67

Walker RT and 5 others (2013) Ice-shelf tidal flexure and subglacial pressure variations. Earth Planet. Sci. Lett., 361, 422-428

Wannamaker PE, Stodt JA and Olsen SL (1996) Dormant state of rifting below the Byrd Subglacial Basin, West Antarctica, implied by magnetotelluric (MT) profiling. Geophys. Res. Lett., 23(21), 2983-2986 (doi: 10.1029/96gl02887) 
Wannamaker PE, Stodt JA, Pellerin L, Olsen SL and Hall DB (2004) Structure and thermal regime beneath the South Pole region, East Antarctica, from magnetotelluric measurements. Geophys. J. Int., 157(1), 36-54 (doi: 10.1111/j.1365246x.2004.02156.x)

Wannamaker PE and 10 others (2012) Magnetotelluric transect of the central transantarctic mountains. In 21st EM induction workshop extended abstract, Darwin, Australia

Ward SH and Hohmann GW (1987) Electromagnetic theory for geophysical applications. In Nabighian MN, ed. Electromagnetic methods in applied geophysics. Soc. Exploration Geophysicists, Tulsa, 131-312

Weertman J (1964) The theory of glacier sliding. J. Glaciol., 5(39), 287-303
Wingham DJ, Siegert MJ, Shepherd A and Muir AS (2006) Rapid discharge connects Antarctic subglacial lakes. Nature, 440(7087), 1033-1036

Woodward J and 9 others (2010) Location for direct access to subglacial Lake Ellsworth: an assessment of geophysical data and modeling. Geophys. Res. Lett., 37(11), n/a-n/a (doi: 10.1029/ 2010GL042884)

Wright A and Siegert M (2012) A fourth inventory of Antarctic subglacial lakes. Antarct. Sci., 24(06), 659-664 (doi: 10.1017/ s095410201200048x).

Zonge KL and Hughes LJ (1985) The effect of electrode contact resistance on electric field measurements. In SEG technical program expanded abstracts 1985. Society of Exploration Geophysicists, 231-234

MS received 9 December 2016 and accepted in revised form 30 May 2017; first published online 27 July 2017 